INRA Prod. Anim.

2013, 26 (2), 129-144

\title{
Les structures supramoléculaires du lait : structure et impact nutritionnel de la micelle de caséine et du globule gras
}

\author{
J. LÉONIL ${ }^{1,2}$, M.-C. MICHALSKI', P. MARTIN ${ }^{4,5}$ \\ 1 INRA, UMR1253 STLO, F-35042 Rennes, France \\ 2 Agrocampus Ouest, UMR1253 STLO, F-35042 Rennes, France \\ 3 INRA USC1235, CarMeN, INSA-Lyon, IMBL, F-69621 Villeurbanne, France \\ 4 INRA, UMR1313 GABI, F-78350 Jouy-en-Josas, France \\ 5 AgroParisTech, UMR1313 GABI, 16 rue Claude Bernard, F-75231 Paris, France
}

Courriel : joelle.leonil@rennes.inra.fr

Le lait, un fluide biologique d'une extraordinaire complexité dans lequel coexiste une multiplicité de molécules dont certaines organisées en structures supramoléculaires parfaitement ordonnées et sources de composés bioactifs.

La glande mammaire d'une vache laitière haute productrice produit quotidiennement une quantité de lait équivalente à $5 \%$ du poids de l'animal. L'alimentation, la génétique et les pratiques d'élevage, mais aussi le processus de différenciation terminale du tissu mammaire peuvent impacter significativement la productivité de l'animal et la composition du lait. L'intense activité de biosynthèse et de sécrétion, dont la glande mammaire est le siège durant la lactation, fait intervenir de nombreux mécanismes complexes de transcription, traduction et sécrétion particulièrement efficaces impliquant un large répertoire de gènes (codants et non codants), dont l'expression peut aujourd'hui être analysée de façon globale et simultanée.

Le lait, est un fluide biologique extrêmement complexe tant par sa nature physique multiphasique (le lait est à la fois une suspension colloïdale, une émulsion et une solution), que par la diversité de ses constituants moléculaires qu'ils s'agissent de sa composante protéique, lipidique, glucidique ou minérale.

Dans le lait, les protéines sont soit solubles $(\alpha$-lactalbumine et $\beta$-lactoglobuline, notamment), soit à l'état de suspension colloïdale. C'est le cas des caséines qui s'associent entre elles et avec le calcium colloïdal pour former les micelles de caséines. S'agissant de la matière grasse laitière, tous les lipides sont rassemblés au sein d'une structure vésiculaire, dérivée de la membrane apicale de la cellule épithéliale : le globule gras. Très récemment d'autres structures vésiculaires, appelées lactosomes, ont été mises en évidence dans le lait. Les globules gras et la micelle de caséine sont des élémentsclés dans la fonctionnalité technologique du lait; or, ni la structure de la micelle ni celle de la membrane du globule gras ne sont encore bien connues.

L'accent sera mis dans cette synthèse sur les avancées concernant la structure de ces macrostructures du lait. Le globule gras, sa sécrétion, sa composition et ses fonctions ayant fait l'objet d'une synthèse dans ce journal en 2007 (Couvreur et Hurtaud 2007), nous nous focaliserons davantage sur les avancées récentes sur la membrane du globule gras et sur les aspects nutritionnels des lipides du lait qui ont fait l'objet de nombreuses recherches au cours des dernières années. Des aspects structuraux, concernant notamment sa structure interne, et nutritionnels seront aussi développés pour la micelle de caséine, vectrice de nombreux peptides bioactifs.

\section{1 / Les structures supramo- léculaires du lait se construi- sent au cours de leur transit intracellulaire}

Pendant la lactation, les Cellules Epithéliales Mammaires (CEM) qui tapissent les structures alvéolaires - ou acini - composant le parenchyme sécrétoire mammaire, synthétisent et exportent vers la lumière des acini de grandes quantités de protéines (notamment les caséines), de lipides, des minéraux et du lactose. C'est la fonction de sécrétion. Les premières étapes de la biogenèse des structures supramoléculaires du lait, micelle de caséine et globule gras, se déroulent dans un même compartiment cellulaire, le Réticulum Endoplasmique (RE). Le RE est le compartiment de biosynthèse de la majorité des lipides cellulaires et des protéines sécrétées, et par conséquent le premier compartiment de la voie de sécrétion. Les gouttelettes lipidiques et les micelles de caséines suivent ensuite deux voies de transport intracellulaire indépendantes (figure 1). Cependant, en fin de processus, la formation de la membrane du globule gras lors de sa sortie dans le milieu extérieur (lumière des acini) se fait aux dépens de la membrane de la cellule, dont l'intégrité est maintenue par l'apport de matériels via la voie de sécrétion des protéines. L'existence d'interactions étroites entre les mécanismes qui gouvernent l'élaboration de ces deux structures est donc hautement probable.

C'est ce qui a été montré chez les caprins, espèce dans laquelle une forte corrélation entre les taux de caséine $\alpha_{\mathrm{s} 1}$ et le taux butyreux a été observée (Barbieri et al 1995), démontrant une corégulation des mécanismes de biosynthèse et/ou de sécrétion des matières grasses et protéiques. L'absence de cette caséine, due à une amputation de près d'un tiers du gène spécifiant cette caséine, perturbe la voie de sécrétion des protéines et induit l'accumulation des autres caséines dans le RE (Chanat et al 1999). Des animaux de ce génotype constituent donc un excellent modèle expérimental pour acquérir des connaissances sur les mécanismes moléculaires qui contrôlent la genèse des 
Figure 1. Principales voies de sécrétion des lipides et des protéines synthétisées par la cellule épithéliale mammaire (adapté de Mather et Keenan 1998).

Les voies $C$ et $A$ correspondent respectivement aux sécrétions des protéines par formation de vésicules sécrétoires puis exocytose (voie $\mathrm{C}$ ) et des lipides par bourgeonnement ou formation de microgouttelettes lipidiques ou "Micro Lipid Droplet ", qui sont sécrétées directement (voie B), ou fusionnent entre elles pour donner des gouttelettes lipidiques cytoplasmiques ou "Cytoplasmic Lipid Droplets " sécrétées par enveloppement dans la membrane plasmique apicale de la cellule (voie A). II est classiquement admis que la membrane des vésicules de sécrétion s'intègre à la membrane plasmique lors de l'exocytose et permet ainsi la reconstitution de la membrane consommée pour l'enrobage des inclusions lipidiques.

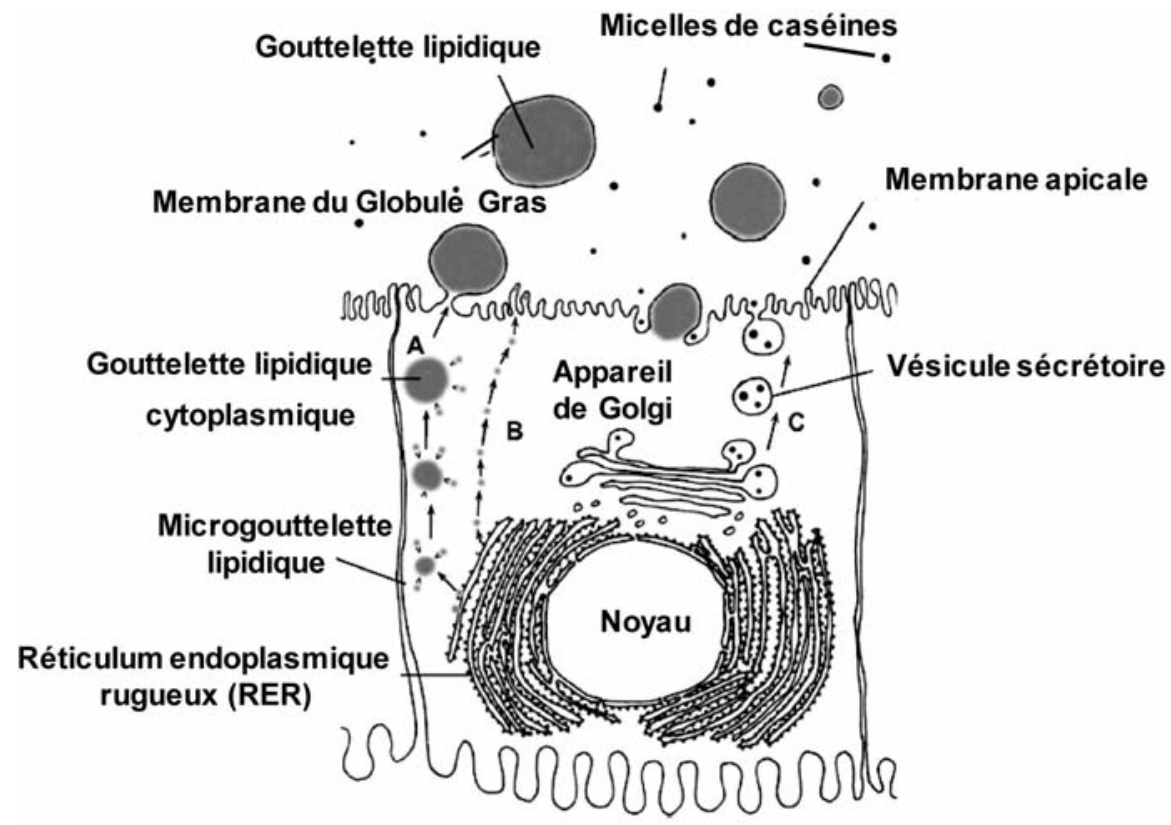

principaux constituants du lait et déterminent leur structure et leurs caractéristiques techno-fonctionnelles.

\section{2 / Les caséines, les gènes qui les spécifient et leur expression}

Les caséines, qui représentent plus de $80 \%$ des protéines du lait chez les ruminants, sont au nombre de quatre : les caséines $\alpha_{\mathrm{s} 1}, \alpha_{\mathrm{s} 2}, \beta$ et $\kappa$. Elles ont évolué rapidement et sont relativement peu d'approches globales telles que la génomique et la protéomique ont mis en évidence la façon dont certains réarrangements à l'échelle du génome et certains polymorphismes génétiques ont façonné l'extrême complexité et la grande variabilité (qualitative et quantitative) de la fraction protéique des laits, entre les espèces, mais aussi au sein d'une même espèce. Les gènes qui spécifient les protéines de la membrane des globules gras du lait («Milk Fat Globule Membrane », MFGM) sont en revanche plus conservés, depuis les monotrèmes jusqu'aux mammifères placentaires, ce qui laisse à penser qu'ils sont cruciaux pour la sécrétion des lipides et que la fonction de sécrétion était déjà établie il y a 150 millions d'années (Lemay et al 2009).

\section{1 / Les caséines}

Les caséines sont des phosphoprotéines synthétisées par la CEM sous contrôle multihormonal complexe. Elles proviennent de l'expression de quatre gènes autosomiques qui spécifient quatre chaînes polypeptidiques distinctes : les caséines $\alpha_{\mathrm{s} 1}, \beta, \alpha_{\mathrm{s} 2}$ et $\kappa$. Ces 4 gènes ( 5 chez certaines espèces, voir ci-après), dont les structures sont maintenant connues dans plusieurs espèces (Rijnkels et al 2003), sont physiquement regroupés, dans cet ordre, sur un même chromosome (le chromosome $6 \mathrm{chez}$ la vache et la chèvre, 5 chez la souris et $4 \mathrm{chez}$ l'Homme), quelle que soit l'espèce. En revanche, la teneur en caséines des laits est très variable. Celles-ci représentent près de $80 \%$ (soit $25-28 \mathrm{~g} / \mathrm{L}$ ) des protéines du lait des ruminants, tandis que, dans le lait humain, leur pourcentage n'excède pas $50 \%$ (soit $4-8 \mathrm{~g} / \mathrm{L}$ ). Avec une teneur qui dépasse $50 \mathrm{~g} / \mathrm{L}$, le lait de brebis, est celui qui présente la teneur en protéines totales la plus élevée des ruminants laitiers. Au-delà de cette variabilité globale, il existe des différences de proportions relatives des caséines, entre les espèces. Ainsi, dans le lait de femme, la caséine $\beta$ est la principale composante de la caséine. A l'inverse,

Tableau 1. Principaux variants génétiques des lactoprotéines majeures dans les principales espèces de ruminants laitiers. Données issues de Ng-Kwai-Hang et Grosclaude (2003), ${ }^{a}$ Bevilacqua et al (2002), b Sacchi et al (2005), ' Prinzenberg et al

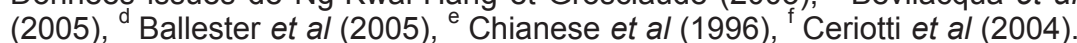

\begin{tabular}{|c|c|c|c|c|c|c|}
\hline & $\begin{array}{c}\text { CSN1S1 } \\
\left.\text { (caséine } \alpha_{\mathbf{s} 1}\right)\end{array}$ & $\begin{array}{c}\text { CSN1S2 } \\
\text { (caséine } \alpha_{\mathrm{s} 2} \text { ) }\end{array}$ & $\begin{array}{c}\text { CSN2 } \\
\text { (caséine } \beta \text { ) }\end{array}$ & $\begin{array}{c}\text { CSN3 } \\
\text { (caséine k) }\end{array}$ & $\beta$-lactoglobuline & $\alpha$-lactalbumine \\
\hline Vache & $\begin{array}{l}7 \text { variants } \\
A-G(+H)\end{array}$ & $\begin{array}{l}4 \text { variants } \\
A-D\end{array}$ & $\begin{array}{c}9 \text { variants } \\
\left(+4 A^{1}, A^{2}, A^{3}, B-G\right. \\
\left(B 2, A^{4}, A^{3} \text { Mong }\right)\end{array}$ & $\begin{array}{c}4 \text { variants } \\
(+5) A, B, C / D \\
\& E(F-J) \\
\end{array}$ & $\begin{array}{l}7 \text { variants } \\
A-G\end{array}$ & 3 variants $A-C$ \\
\hline Chèvre & $\begin{array}{c}13 \text { variants }{ }^{a} \\
(+ \text { allèles nuls })\end{array}$ & $\begin{array}{l}6 \text { variants }{ }^{b} \\
(+1 \text { allèle nul })\end{array}$ & $\begin{array}{c}3 \text { variants } \\
\text { (+ allèles nuls) }\end{array}$ & 13 variants $^{c}$ & $\begin{array}{l}\text { Pas de variants } \\
\text { caractérisés }^{d}\end{array}$ & - \\
\hline Brebis & $\begin{array}{c}5 \text { variants } \\
A-E\end{array}$ & $\begin{array}{c}3 \text { variants }{ }^{e} \\
A-C\end{array}$ & 2 variants ${ }^{f}$ & 2 variants ${ }^{f}$ & $\begin{array}{l}3 \text { variants } \\
A-C\end{array}$ & $\begin{array}{c}2 \text { variants } \\
A \& B\end{array}$ \\
\hline
\end{tabular}


la caséine $\alpha_{\mathrm{s} 1}$ est la caséine majoritaire dans le lait de lapine. Les laits de ratte, de truie et de vache contiennent environ la même proportion de caséines $\beta$ et $\alpha_{\mathrm{s}}$. Le lait de femme ne contient pas de caséine $\alpha_{\mathrm{s} 2}$.

Au-delà de cette grande variabilité quantitative, il convient de souligner la faible conservation des séquences orthologues (issues d'un même gène) entre les espèces. La fraction « caséine » des laits est donc un système complexe et spécifique qui mérite d'être considéré en termes de diversité. De plus, les modifications post-traductionnelles, telles que la phosphorylation, glycosylation, et une protéolyse limitée par la plasmine, augmentent l'hétérogénéité de ce système qui se complexifie encore en raison de l'existence de nombreux variants génétiques.

\section{2 / Le locus caséine (CSN) et la variabilité de la composition caséinique des laits}

L'analyse comparative de l'organisation du locus « caséine » (figure 2) révèle une remarquable conservation entre les espèces, depuis les mammifères ancestraux tels les monotrèmes (ornithorynque) jusqu'aux mammifères placentaires (Warren et al 2008). Les quatre (ou cinq) gènes sont confinés dans un segment chromosomique de 250-350 kb situé sur le chromosome 6 dans les espèces bovine et caprine et disposés dans l'ordre $\alpha_{\mathrm{s} 1}, \beta, \alpha_{\mathrm{s} 2}$ et $\kappa$ (Martin et al 2002). Malgré quelques différences dans les distances séparant les gènes et leur nombre, l'organisation générale du locus est remarquablement conservée.

Les trois gènes (CSN1S1, CSN1S2 et CSN2) spécifiant les caséines sensibles au calcium $\left(\alpha_{\mathrm{s} 1}, \alpha_{\mathrm{s} 2}\right.$ et $\left.\beta\right)$, dérivent d'un ancêtre commun et partagent un même motif dans la partie proximale de la région $5^{\prime}$ adjacente à l'unité de transcription (Groenen et al 1993). Bien que l'organisation de la région 5' adjacente du gène CSN3 qui spécifie la caséine $\kappa$ soit différente (Coll et al 1995), son profil d'expression est similaire à celui des autres gènes. Il apparaît qu'un même jeu de facteurs de transcription est nécessaire au contrôle de l'expression des gènes spécifiant les protéines du lait et particulièrement les caséines.

La transcription n'est pas le seul niveau auquel la régulation de l'expression génique peut s'exercer. De nombreux autres facteurs agissant au niveau posttranscriptionnel, en particulier sur la maturation des ARN messagers et leur stabilité, ainsi que sur leur traduction, interviennent également (Bevilacqua et al 2006, Rhoads et Grudzien-Nogalska 2007). Les régions « codantes » des gènes des vertébrés, y compris ceux des caséines chez les mammifères, ont une structure interrompue par des séquences « non-codantes » ou introns. La plupart des ARN messagers eucaryotes sont transcrits en tant que précurseurs (pré-messagers) contenant ces séquences introniques qui doivent être excisées pour générer des ARNm matures et fonctionnels. Le processus d'élimination des introns et de ligation des exons ou épissage, est une fonction importante assurée par une structure complexe appelée spliceosome. Ce mécanisme précis et efficace est régi par un ensemble de règles assez strictes qui permettent en théorie d'atteindre un niveau élevé de fidélité. Cependant, de nombreux variants d'épissage ont été décrits dans pratiquement toutes les espèces, en particulier pour les caséines dont les gènes morcelés sont particulièrement propices à ce type d'événement (utilisation de sites cryptiques d'épissage, "exon-skipping »). Des dysfonctionnements plus ou moins constitutifs de ce mécanisme et des déviations aux patrons de modifications post-traductionnelles (phosphorylation, glycosylation), viennent s'ajouter pour produire un système d'une extrême complexité dont les conséquences biologiques peuvent être lourdes du fait de la modification du message et in fine de la structure de la protéine.

Il n'est évidemment pas réaliste de passer ici en revue tous les cas d'espèce.

Figure 2. Conservation de l'organisation fonctionnelle du locus « caséines » au cours de l'évolution.

Les gènes sont représentés par des boîtes en forme de flèches indiquant le sens de transcription. Les boîtes vides représentent des gènes putatifs dont la présence et l'expression restent à démontrer. La taille des régions intergéniques est donnée (en rouge) en kilobases $(\mathrm{kb})$. Les loci humain et équin ont sensiblement la même taille (320-330 kb) alors que le locus bovin est sensiblement plus court (250 kb). Les gènes STATH (Stathérine) HTN3 et HTN1 (Histatines) ont une origine commune et spécifient des protéines qui ont un effet protecteur sur les dents en régulant la précipitation spontanée de sels de phosphate de calcium à la surface de l'émail (Kawasaki et Weiss 2003). Le gène ODAM qui spécifie une « ODontogenic AMeloblast-associated protein » vraisemblablement impliquée dans l'odontogénèse est très conservée au cours de l'évolution et est exprimée dans plusieurs tissus épithéliaux (Moffatt et al 2008).
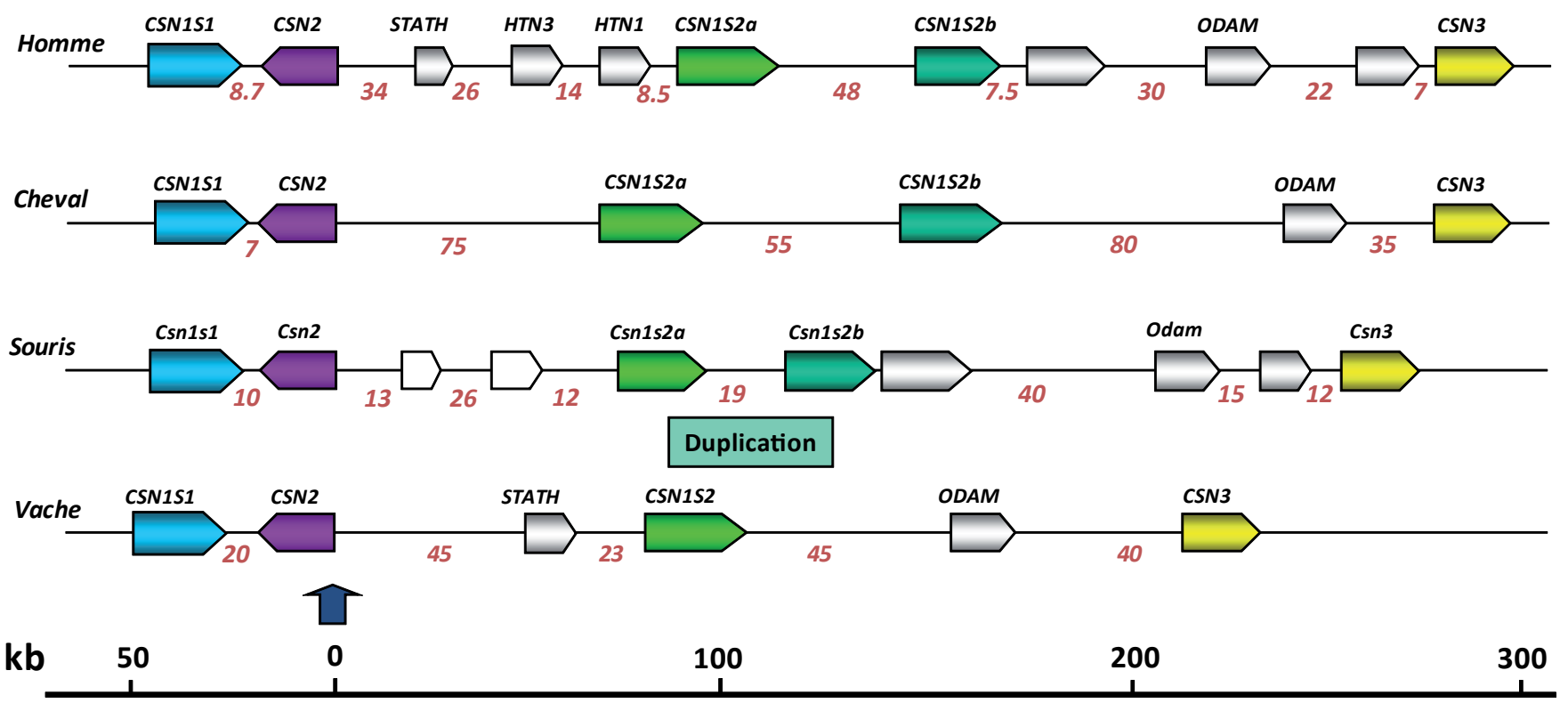
Certains modèles sont plus riches d'enseignements que d'autres et peuvent apporter un éclairage pertinent dans plusieurs directions. Nous avons choisi d'analyser ces facteurs de variabilité au travers de quelques exemples particulièrement démonstratifs, de façon à en évaluer l'ampleur et l'impact sur la structure de la micelle et sur les propriétés de la matière première que les industriels sont amenés à transformer.

a) Le locus CSN1S1 : un gène morcelé pour partie responsable de la complexité et de la variabilité de la fraction protéique des laits et de la diversité structurale interspécifique

Plus de 15 allèles ont à ce jour été décrits et caractérisés au locus spécifiant la caséine $\alpha_{\mathrm{s} 1}$ (Bevilacqua et al 2002). Ils se répartissent en 7 classes différentes de variants protéiques, dont certains sont profondément modifiés dans leur structure primaire (variants $\mathrm{F}$ et $\mathrm{G}$, respectivement délétés de 37 et 13 résidus d'acides aminés), associés à 4 niveaux d'expression (Grosclaude et Martin 1997). Les mutations responsables de ce polymorphisme ont été identifiées, notamment pour les allèles défectifs (Martin et al 1999).

L'allèle F (prototype de l'allèle défectif) n'est exprimé qu'à un faible taux $(0,6 \mathrm{~g} / \mathrm{L}$ et par allèle), alors que celui dont il dériverait, l'allèle $\mathrm{B}_{2}$, qui appartient à la classe des allèles « forts ", produit environ $3,6 \mathrm{~g}$ de caséine $\alpha_{\mathrm{s} 1}$. Ainsi, deux individus homozygotes pour ces allèles présenteront un différentiel d'environ $6 \mathrm{~g}$ de caséine $\alpha_{\mathrm{s} 1}$ par litre de lait (soit un écart de $25 \%$ sur le taux de caséines). Pas moins de 9 ARN messagers différents, correspondant à des variants d'épissage d'un même transcrit primaire, ont été caractérisés dans le tissu mammaire d'individus homozygotes $\mathrm{F} / \mathrm{F}$ au locus CSN1S1 (Leroux et al 1992). Parmi ces transcrits matures, on trouve aussi bien des ARNm correctement épissés que des messagers dans lesquels il peut manquer jusqu'à 5 exons sur les 19 que compte le gène. Ces défauts d'épissage (« exon-skipping ») sont soit de nature
" accidentelle » : c'est le cas des exons 13 et 16 qui sont aussi parfois éliminés au cours du processus de maturation des transcrits primaires issus d'allèles non défectifs comme l'allèle A par exemple (Ferranti et al 1997); soit de nature " constitutive » ou allélique, consécutive à un événement mutationnel localisé, tel que la délétion d'un simple nucléotide dans une séquence codante (c'est le cas de l'exon 9 qui ne compte, chez l'allèle $F$, que 32 nucléotides au lieu de 33).

On relève également des erreurs dans la reconnaissance des sites d'épissage (utilisation de sites cryptiques), conduisant généralement à la perte d'un codon en début d'exon, ou encore un changement de cadre de lecture avec l'apparition d'un codon stop prématuré et donc la synthèse d'une protéine hybride et tronquée. La seconde conséquence de ce dysfonctionnement est une réduction sensible de la quantité de messagers (dégradation des ARNm non conformes : " $m R N A$ decay »), donc de synthèse protéique.

Figure 3. Alignement des séquences en acides aminés des caséines $\alpha_{s} 1$ de vache, de jument, de femme, de truie et de lapine, prenant en compte l'organisation exonique du gène spécifiant la protéine dans les espèces (vache, chèvre, lapin et homme) pour lesquelles cette organisation est connue.

Les séquences peptidiques sont décomposées en segments correspondant aux exons « codants » des gènes. La numérotation des exons est celle utilisée pour les gènes bovin (Koczan et al 1991) et caprin (Leroux et al 1992). Les exons additionnels détectés chez le lapin (Jolivet et al 1992) et l'Homme (Martin et al 1996) sont indiqués en "' ». La séquence de la caséine $\alpha_{S 1}$ de porc est celle publiée par Alexander et Beattie (1992). Les résidus d'acides aminés en italiques et gras correspondent au peptide signal dont le site de clivage est indiqué par la flèche verticale. Les boîtes de couleur dans les blocs exoniques matérialisent les exons absents ou spécifiquement et constitutivement éliminés au cours du processus de maturation des transcrits primaires.

\begin{tabular}{|c|c|c|c|c|c|c|c|c|}
\hline & exon 2 & 1 & exon 3 & exon 3' & exon 4 & exon 5 & exon 6 & exon $6^{\prime}$ \\
\hline Bovin & MKLLILTCLVAVALA & $\mathrm{RP}$ & KHPIKHQGLPQ & $\square$ & -EVLNEN-LLRFFVA & PFPEVFGK & EKVNELSK & \\
\hline Équin & MKVFI IACLVAVALA & $\mathrm{RL}$ & KLPHRQPEIIQ & NEQDSRE & -KVLKERKPF-SFAL & $\square$ & EYINELNR & QRELLKEKQKDEHK \\
\hline Humain & MKLLIFTCLVAVALA & $\mathrm{RP}$ & KLPLRYPERLQ & NPSESSE & $\square$ & PIPLESRE & EYMNGMNR & QRNILREKQTDEIK \\
\hline Porcin & MKLI IFICLAAVALA & $R P$ & KPPLRHQEHLQ & NEPDSRE & -ELFKERKF'LRF'PEV & PLISQFRQ & EIINELNR & \\
\hline Lapin & MKLLILTCLVATALA & $\mathrm{RH}$ & KFHLGHLKLTQ & EQPESSE & QEILKERKLLRF-VQ & TVPLELRE & EYVNELNR & QRELLREKENEEIK \\
\hline
\end{tabular}

\begin{tabular}{|c|c|c|c|c|c|c|c|c|}
\hline & exon 7 & exon 8 & exon 9 & exon 10 & exon 11 & exon 12 & exon 13 & exon 13' \\
\hline Bovin & DIGSESTE & DQAMEDIK & QMEAESISSSE & EIVPNSVE & QKHIQKE-DVPSERYLGYL & -EQLLRLK-KYKVPQL & EIVPNSAE & \\
\hline Équin & DTSNESTE & EYLIEDPE & QQESSSTSSSE & EVVPINTE & -KRIPRE-DML---YQHTL & -EQLRRLS-KYNQLQL & & QAIHAQ \\
\hline Humain & DTRNESTQ & NCVVAEPE & KMESSISSSSE & EMSLSKCA & & -EQFCRLNE-YNQLQL & & QAAHAQ \\
\hline Porcin & & NHGMEGHE & Q-RGSSSSSSE & EVVGNSAE & QKHVQKEEDVPS---QSYL & -GHLQGLN-KYKLRQL & & EAIHDQ \\
\hline Lapin & GTRNEVTE & EHVLADRE & -TEASISSSSE & EIVPSSTK & QKYVPRE-DLA---YQPYV & QQQLLRMKERY-QIQE & & \\
\hline
\end{tabular}

exon 14 exon 15

exon 16

exon 17

exon 18

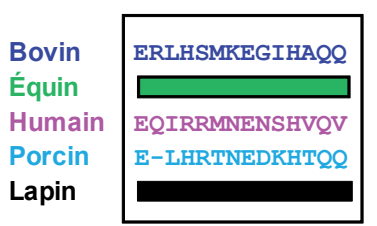

ELAYFYPE

EQAYFYLE

EOAYFYFE

ELAQLYLQ
LFRQFYQLDAYPSGAWYY-PLGTQYTDAPSFSD IPNPIG SENSEKTT-MPLW-

LFRQSYQLDVYPYAAWFHPAQIMQHVAYS PFHD TAKLIASENSEK TDIIPEWPFQQLNQLAAYPYAVWYYPPQIMQYVPFP PFSD I SNPTAHENYEKNNVMLQWPLHQFYQLDAYPYATWYYVP --- QYIAHPL FTNI PQPTAPEKG GKTEIMPQWPFEQPYQLDAYLPAPWYYGPEVMQYVLSPLFYDLVTPSA FESAEKTDVIPEWL 
Les modifications post-traductionnelles, en particulier la phosphorylation s'agissant des caséines sensibles au calcium $\left(\alpha_{\mathrm{s} 1}, \beta\right.$ et $\left.\alpha_{\mathrm{s} 2}\right)$, constituent une source supplémentaire d'hétérogénéité. Trois niveaux de phosphorylation ont été rapportés pour la caséine $\alpha_{\mathrm{s} 1}$ caprine (7 à 9 groupements phosphate pour le variant A). Les résidus Ser41 et Ser115 ne sont qu'incomplètement (respectivement 20 et $50 \%$ ) phosphorylés (Ferranti et al 1997).

\section{b) Variabilité interspécifique}

Si l'on considère cette même caséine en faible quantité ( 1 à $2 \mathrm{~g} / \mathrm{L}$ ) dans le lait de femme, il apparait qu'elle est sensiblement plus courte (170 résidus d'acides aminés) et qu'elle présente assez peu de similarités (de l'ordre de 30\%) avec les caséines $\alpha_{\mathrm{s} 1}$ d'autres espèces.

L'analyse de l'organisation du gène humain et la prise en compte de la structure modulaire des ARN messagers ont conduit à conclure que la similarité réelle avec les autres caséines est significativement plus élevée et que cette apparente divergence est en fait due à une combinatoire d'épissage propre à chaque espèce (Martin et al 1996). Le cumul des similarités sur les 11 blocs exoniques codants partagés par les espèces bovine et humaine (figure 3) conduit à un degré d'homologie qui approche les $50 \%$. Des travaux effectués dans l'espèce équine confortent cette analyse (Milenkovic et al 2002, Miranda et al 2004) et confirment l'exis-

Figure 4. Patron d'épissage du gène spécifiant la caséine $\beta$ équine qui compte 226 résidus d'acides aminés dans sa forme mature complète.

Le gène se compose de 9 exons dont 6 " codants " (gris et bleu : peptide signal). Les exons « non-codants » (1,8 et 9$)$ sont en turquoise. La numérotation des exons est celle utilisée pour le gène bovin (Bonsing et al 1988). Le site cryptique d'épissage interne à l'exon 7 est indiqué par la flèche verticale. L'utilisation de ce site cryptique d'épissage dans l'exon 7 conduit à la synthèse d'une protéine de 94 résidus d'acides aminés (partie supérieure de la figure). L'élimination (« skipping ») de l'exon 5 conduit à la synthèse d'une protéine de 218 résidus d'acides aminés (partie inférieure de la figure).

Les formes ovales, le triangle et le losange, placés en amont de l'unité de transcription (" promoter region ») correspondent aux facteurs qui modulent la transcription du gène. La forme ovoïde jaune localisée dans le premier intron du gène correspond au site de fixation d'un activateur d'épissage intronique (ISE : "Intronic Splicing Enhancer »).

\section{ISE : Intron Splicing Enhancer}

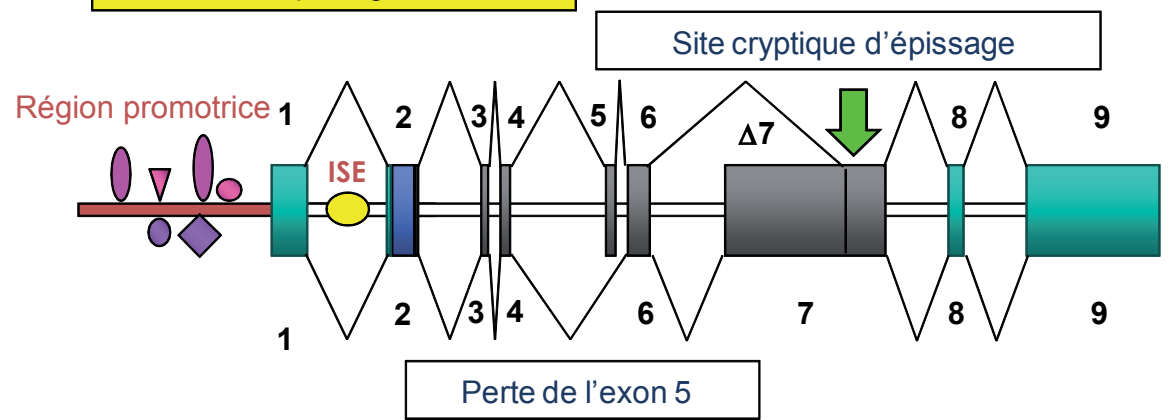

autour de 150 à $200 \mathrm{~nm}$ (Holt 1985, Dalgleish et Corredig 2012). Cette micelle est composée de $90 \%$ de caséine et de $8 \%$ de minéraux. Les quatre caséines qui la composent, les caséines $\alpha_{\mathrm{s} 1}, \alpha_{\mathrm{s} 2}, \beta$ et $\kappa$, sont dans un rapport molaire respectif de $4 ; 1 ; 3,5$ et 1,5 . La fraction minérale est constituée à $90 \%$ de phosphate de calcium et à $10 \%$ d'ions magnésium et citrate. Le phosphore lui-même comprend deux fractions: la fraction inorganique sous la forme d'un orthophosphate et la fraction organique qui correspond au phosphate lié aux caséines par estérification des résidus sérine (Walstra et Jenness 1984). Les autres sels, le calcium et le magnésium, se répartissent également dans deux fractions, une liée aux résidus phosphosérines et aux groupements carboxyles des protéines et l'autre organisée en un complexe composé de phosphate, de citrate, de calcium et de magnésium, appelé Phosphate de Calcium Colloïdal (PCC). La composition et la structure du PCC ne sont toujours pas élucidées.

La structure de cette micelle de caséine reste un sujet de discussion et fait encore débat, en dépit des nombreux travaux qui lui ont été consacrés comme en témoignent les revues récentes sur ce thème (Holt 1992, Horne 2006, McMahon et Oommen 2008, Dalgleish 2011, de Kruif et al 2012). Depuis les années soixante, plus d'une dizaine de modèles de structure micellaire ont été décrits autour de deux variantes : le modèle à sous-unités (ou modèle à sub-micelles) et le modèle à « nanoclusters » (ou modèle à structure ouverte). Ces deux modèles se rejoignent, d'une part sur la localisation de la caséine $\kappa$ à la surface de la micelle dont les chaines C-terminales constituent une couche " chevelue » qui permet de stabiliser la micelle et, d'autre part sur la porosité de la structure micellaire.

\section{1 / Le modèle à sous-unités ou à sub-micelles}

Le modèle à sous-unités a été développé à partir de données expérimentales issues d'études sur la dissociation de la micelle et d'observations morphologiques en microscopie. Le modèle « cœur-couronne " originel constitué des caséines $\alpha_{\mathrm{S}}$ et $\beta$ entouré par une couche de caséine $\kappa$ (Waugh et al 1970) a progressivement évolué pour aboutir au modèle très connu de Schmidt (1982). La micelle est assimilée à une sphère composée de sousunités protéiques, elles-mêmes sphériques dont la taille varie entre 10 et $20 \mathrm{~nm}$. Les sous-unités auraient une composition variable avec un cœur hydrophobe et une couche externe constituée des régions polaires des caséines, les résidus chargés seraient donc exposés à la surface de la sous-unité. Les sous-unités seraient reliées par le PCC pour former 
Figure 5. Les deux modèles proposés pour la structure de la micelle de caséine.

Modèle à sous-unités : les grains figurent le phosphate de calcium colloïdal. Les cercles représentent les sous-unités et les filaments l'extrémité de la caséine $\kappa$.

Modèle à structure ouverte : les grains figurent les nanoclusters distribués dans une matrice de caséines. Les filaments à la surface représentent l'extrémité de la caséine $\kappa$.
Modèles à sous-unités

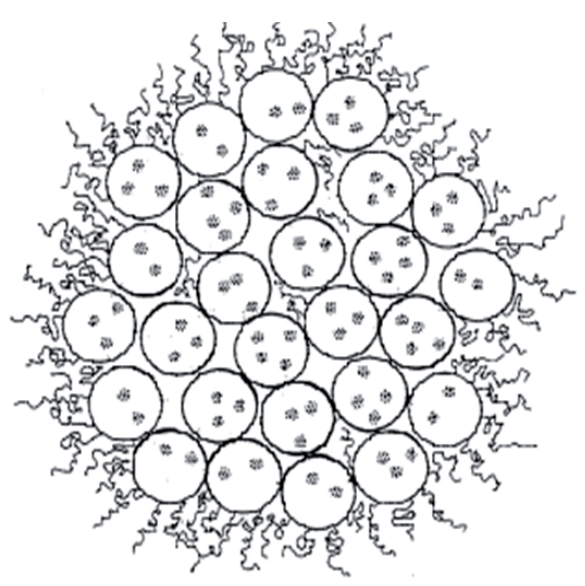

Walstra (1999)
Modèles à structure ouverte

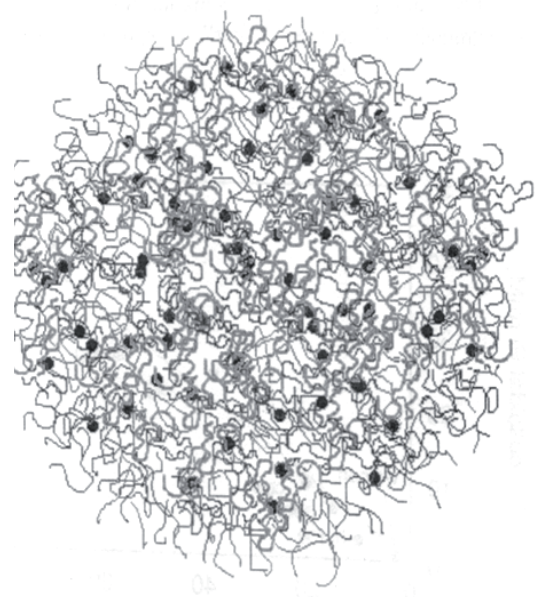

De Kruif et Holt (2003) la micelle de caséines. Il existerait deux types de sub-micelles : celles constituées de caséines $\alpha_{\mathrm{s}}$ et $\beta$ au cœur de la micelle et celles constituées de caséines $\alpha_{\mathrm{s}}$ et $\kappa$ (Ono et Obata 1989). Les sous-unités riches en caséine $\kappa$ se situeraient préférentiellement à la surface de la micelle. La partie C-terminale hydrophile de la caséine $\kappa$ (le caséino-macropeptide) forme une couche de « cheveux » flexibles à la surface de la micelle stabilisant la structure colloïdale par répulsions électrostatiques et stériques entre les micelles en suspension (Walstra et Jenness 1984). La variante la plus récente de ce modèle est celle de Walstra (1999) reprenant le modèle sub-micellaire contenant des sous-unités d'une taille comprise entre 15 et $20 \mathrm{~nm}$ dans lequel le phosphate de calcium ferait partie intégrante des submicelles sous forme de microgranules (figure 5). Des interactions, notamment hydrophobes, assureraient la cohésion au sein des sous-unités (Walstra 1999).

\section{2 / Le modèle à « nanoclusters » ou à structure ouverte}

La micelle est décrite dans ce modèle comme un réseau construit à partir d'un point de nucléation qui s'est développé grâce aux interactions entre le calcium et les différentes caséines. Ce point de nucléation est constitué de nanoclusters qui sont des substructures de 2,3 nm constituées de calcium stabilisé par des interactions avec les groupements phosphoséryles des caséines notamment $\alpha_{\mathrm{s}}$ et $\beta$ (Holt 1998). La micelle se construirait par un processus d'interactions non des expériences de diffusion de la lumière et seul le modèle à structure ouverte est en adéquation avec les données quantitatives obtenues (de Kruif et al 2012). Il ressort de cette analyse qu'il n'existe aucune substructure dans la micelle. La distribution de masse est homogène dans la micelle avec des régions de plus ou moins grande densité et la seule hétérogénéité serait liée à la présence des nanoclusters (de l'ordre de $2 \mathrm{~nm}$ ) dispersés dans la matrice et distants en moyenne de $18,6 \mathrm{~nm}$ soit un total de 286 à 372 nanoclusters par micelle de caséine (de Kruif et al 2012). L'assemblage protéique est thermodynamiquement stable par l'effet coopératif des interactions faibles entre les caséines et la stabilisation stérique assurée par la caséine $\kappa$. La présence de régions de plus ou moins grande densité est à la base du modèle hiérarchique triple proposé par Bouchoux et al (2010) : le premier niveau étant les nanoclusters; le niveau intermédiaire basé sur des régions de forte densité constituées de caséines et de phosphates réparties dans une matrice comme une éponge et enfin le troisième niveau étant la micelle elle-même d'un diamètre moyen de $100 \mathrm{~nm}$. Les microscopies électroniques à forte résolution comme la cryo-microscopie à transmission, qui ne souffrent pas des artéfacts habituellement liés à la préparation des échantillons (fixation, coloration), ne montrent pas la présence de sub-micelles (Marchin et al 2007, McMahon et Oommen 2008).

Les images tomographiques à trois dimensions obtenues récemment par la cryo-microscopie à transmission montrent la présence de cavités remplies d'eau de 20 à $30 \mathrm{~nm}$ de diamètre et des canaux d'environ 6 à $12 \mathrm{~nm}$. Ces images visualisent la présence de petites particules attribuées aux nanoclusters de 6 à $12 \mathrm{~nm}$ de diamètre (Trejo et al 2011). D'autres techniques comme la résonance plasmonique de surface, qui permet de sonder la surface de la micelle au travers de sondes fonctionnalisées avec des anticorps anti-caséines, ont permis de conforter la présence de toutes les caséines à la surface de la micelle (Dupont et al 2011).

Durant ces dernières années, il ressort que la contribution importante des techniques de la physique de la matière molle a été de fournir des données quantitatives - pour étayer les représentations de structures basées jusqu'alors sur l'imagination des chercheurs - ou d'ordre conceptuel. Si la physique plaide plutôt en faveur d'un modèle à structure ouverte, la biologie semble faire prévaloir le modèle à sousunité sur la base des observations morphologiques de la micelle dans la cellule épithéliale mammaire. Une analyse détaillée sur ce dernier point est fournie dans la revue de Farrell et al (2006). 
Il apparait actuellement difficile d'accepter un modèle et d'éliminer complètement l'autre car aucun des modèles ne donne une description au niveau moléculaire permettant de comprendre l'organisation interne de la micelle. C'est certainement une meilleure connaissance du rôle de chacune des caséines dans l'élaboration de la structure micellaire, à l'exemple des travaux menés sur le rôle de la caséine $\alpha_{\mathrm{s} 1}$, qui contribuera à comprendre l'organisation de cette suprastructure hiérarchique dans la voie de sécrétion (Chanat et al 1999, Le Parc et al 2010).

\section{4 / Impact nutritionnel}

\section{a) Peptides bioactifs d'origine laitière}

La micelle de caséine est un acteur clef dans les propriétés technologiques du lait et a fait l'objet de plusieurs ouvrages (Walstra et al 1999, Jeantet et al 2008). En revanche, la fonction biologique de la micelle n'est pas connue avec certitude, mais on lui attribue le rôle primordial de vectorisation du calcium pour le développement du nouveau-né. Des études suggèrent également qu'une de ses fonctions serait de prévenir la calcification de la glande mammaire en séquestrant le phosphate de calcium afin d'éviter ainsi sa précipitation (de Kruif et Holt 2003). La fonction de la micelle de caséine mérite d'être reconsidérée en terme de potentiel biologique, en particulier à la lumière du nombre croissant de peptides biologiquement actifs dérivés des caséines qui ont été identifiés au cours des 25 dernières années (Maubois et Léonil 1989, Clare et Swaisgood 2000, Meisel 2005). Ces peptides sont capables de moduler des fonctions de l'organisme en agissant par exemple sur la digestion, le système nerveux central et périphérique, le système immunitaire et cardiovasculaire. Ils présentent des activités opiacées, anti-hypertensives, anti-thrombotiques, immuno-modulatrices, anti-virales, antimicrobiennes et sont aussi capables d'agir sur l'absorption des minéraux, la sécrétion des hormones digestives ou de mucines intestinales (Phelan et al 2009). Les mêmes activités se retrouvent au sein de peptides issus des protéines solubles du lait. Il faut signaler que ces peptides sont présents chez toutes les espèces laitières. L'étude des peptides bioactifs a été un domaine de recherche très actif en raison du potentiel que ceux-ci pouvaient présenter pour le développement d'aliment-santé. Par conséquent, un grand nombre de peptides bioactifs a été identifié et leurs séquences ont été répertoriées dans des bases de données (BIOPEP). Les peptides bioactifs ont généralement entre 2 et 20 acides aminés à l'exception du caséino-glycomacropeptide correspondant au 1/3 C-terminale de la caséine $\kappa$ (séquence 106-169), qui compte 64 résidus d'acides aminés. Ils sont libérés par hydrolyse enzymatique (enzymes gastro-intestinales, enzymes ajoutées au lait au cours des procédés de transformation ou issues des bactéries lactiques). Des quantités de peptides bioactifs de l'ordre de la centaine de $\mathrm{mg} / \mathrm{kg}$ ont été trouvées dans certains fromages et souvent dans des fromages à pâtes pressées.

Plusieurs revues récentes de la littérature ont été consacrées aux peptides bioactifs du lait, (Korhonen 2009, RicciCabello et al 2011), aussi cet aspect sera décrit sans exhaustivité ci-dessous en ciblant ceux qui ont été particulièrement étudiés.

Peptides anti-hypertensifs : ces peptides inhibent l'activité de l'enzyme de conversion de l'angiotensine (ECA) dans les tests in vitro. L'ECA est une enzyme clef dans la régulation de la pression artérielle en agissant sur le système rénine-angiotensine ; l'angiotensine II étant un vasoconstricteur puissant. Ces activités sont retrouvées dans les caséines $\alpha_{s} 1, \beta$ et $\kappa$ ainsi que dans la $\beta$-lactoglobuline, l' $\alpha$ lactalbumine et la sérum albumine. Les peptides les plus étudiés sont deux tripeptides, Val-Pro-Pro et Ile-Pro-Pro, issus de la caséine $\beta$. Leur efficacité a été démontrée chez l'Homme dans le cadre d'un régime alimentaire et a donné lieu à une exploitation commerciale de produits laitiers fermentés à effets antihypertensifs au Japon, en Finlande et aux Etats-Unis.

Peptides anti-thrombotiques : ces peptides sont présents dans la caséine $\kappa$ en position (106-116, 109-111) et la lactoferrine (39-42). Ils inhibent l'agrégation plaquettaire et se sont révélés actifs en injection intraveineuse dans un modèle de thrombus artériel chez l'animal. Malgré leur intérêt potentiel sur la diminution du risque cardio-vasculaire, l'administration orale de ce peptide dans le cadre d'un régime alimentaire n'a pas fait l'objet d'étude chez l'Homme.

Peptides opioïdes : les plus connus sont une famille de peptides, les $\beta$-casomorphines (séquence 60-66), issue de la caséine $\beta$. Ils agissent sur la motilité intestinale, la vidange gastrique et les sécrétions gastro-intestinales. Ces effets ont été démontrés chez l'animal et n'ont quasiment pas fait l'objet d'étude chez l'Homme probablement en raison des effets multiples de ces peptides, qui agissent sur plusieurs cibles physiologiques.

Phosphopeptides du lait: ces séquences portent des clusters de phosphoserine, leurs permettant de solubiliser des minéraux comme le calcium et des oligoéléments (fer, zinc, magnésium...). Cette propriété leur permet de favoriser l'absorption de ces minéraux. Cet effet a été démontré chez l'animal. En revanche, les études chez l'Homme ont donné lieu à des résultats contradictoires. Les études actuelles sont plutôt axées sur les propriétés anti-cariogéniques des phosphopeptides du lait, qui provoquent une reminéralisation de l'émail des dents. Cette activité est exploitée actuellement dans le domaine des soins dentaires.

Peptides immunomodulateurs : ces peptides sont capables de stimuler la prolifération des lymphocytes, la phagocytose par les macrophages et la production de cytokines. Ces activités potentiellement intéressantes pour renforcer le système immunitaire ont fait l'objet de peu d'études chez l'Homme, une des difficultés majeures étant de trouver les biomarqueurs adéquats de la réponse immunitaire.

Les perspectives de développement de l'utilisation des peptides bioactifs du lait nécessitent probablement d'approfondir les connaissances sur leur mode d'action et les mécanismes de signalisation qui sont mis en place au niveau intestinal, car de nombreuses études apportent la preuve de leur présence dans le tractus gastro-intestinal suite à la consommation de protéines de lait et de produits laitiers (Phelan et al 2009).

\section{b) Spécificité nutritionnelle des protéines du lait}

En terme nutritionnel, un des résultats marquants est la découverte du concept de protéines lentes et rapides (Boirie et al 1997). Lorsque les protéines du lait sont ingérées sous forme de caséines ou de protéines solubles, il apparaît que les acides aminés de la caséine sont libérés et absorbés plus lentement que ceux des protéines solubles chez l'Homme, ce qui se traduit par une meilleure efficacité des caséines sur l'anabolisme postprandial. Les caséines sont uniques par rapport à leur comportement digestif car elles sont les seules à précipiter dans l'estomac. Ces connaissances ouvrent de nouvelles perspectives nutritionnelles car elles peuvent permettre d'optimiser la réponse protéique postprandiale chez l'Homme, voire de faciliter le gain protéique à long terme de populations dont le capital protéique peut être dangereusement affecté.

\section{4 / Les lipides du lait : une composition complexe et structurée au fort potentiel nutritionnel}

La matière grasse laitière représente une source de lipides importante dans l'alimentation des français (AFSSA 2009, FAPRI 2009). Celle-ci a pourtant long- 
Figure 6. Différents niveaux de structure de la matière grasse laitière (adapté de Michalski 2009 et Lopez 2011).

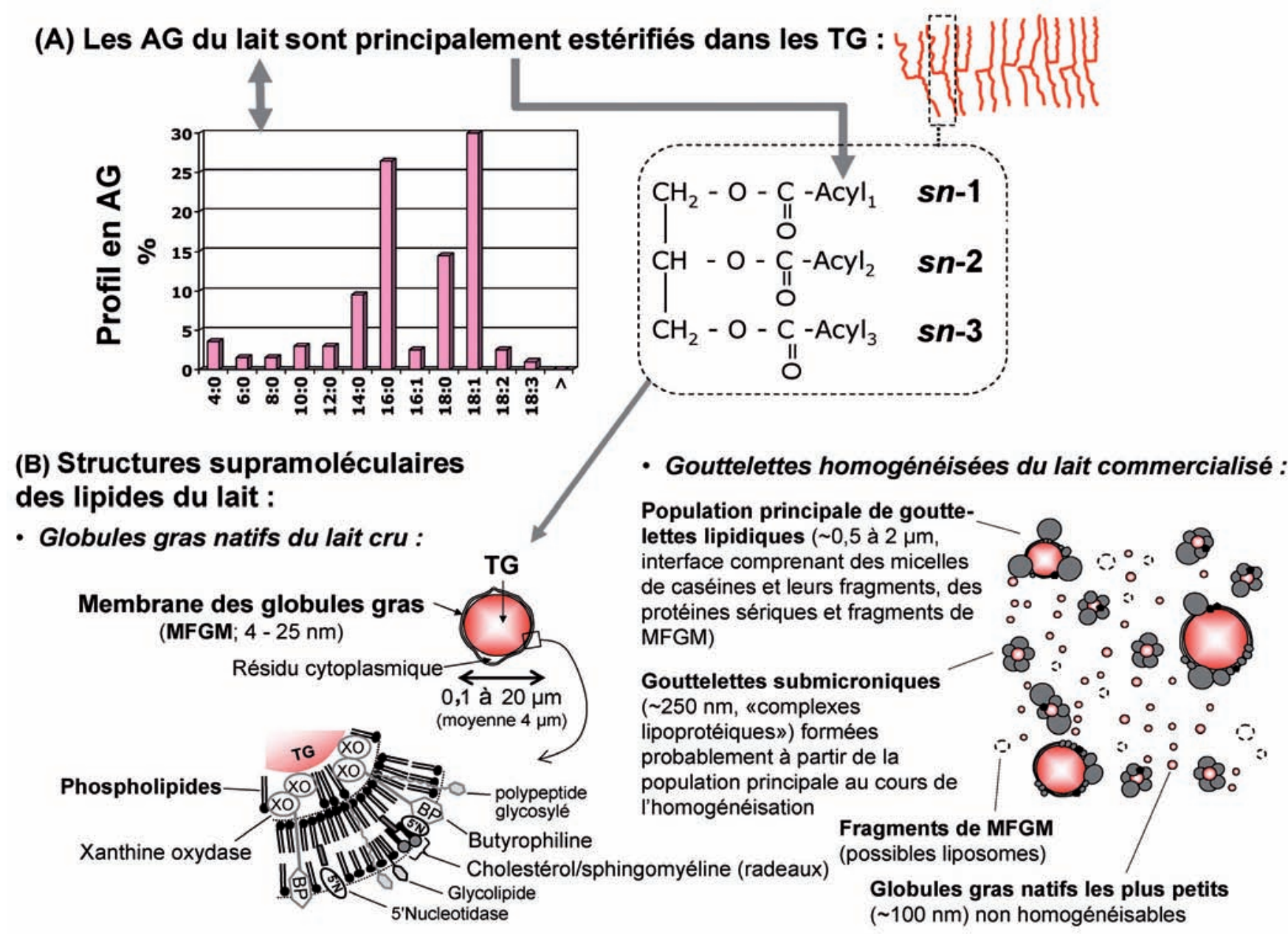

temps été décriée dans le contexte du développement de pathologies notamment cardiovasculaires, du fait de sa richesse en acides gras saturés à chaîne longue comme l'acide palmitique. Cependant, les études récentes tendent à disculper les lipides laitiers et à mettre en avant leur richesse en nutriments lipidiques mineurs au potentiel bioactif (Aslibekyan et al 2012). La spécificité de leur organisation supramoléculaire dans les aliments est aussi un élément important longtemps négligé et mieux pris en compte aujourd'hui dans l'analyse de leurs propriétés nutritionnelles (RaynalLjutovak et al 2011). Le lait contient 3 à $5 \%$ de lipides (Jensen 2002). Comme dans l'alimentation en général, plus de 95\% des lipides laitiers sont des triacylglycérols ou TriGlycérides (TG), apportant chacun trois molécules d'Acides Gras (AG), estérifiés sur une molécule de glycérol (figure 6A). D'autres lipides mineurs d'importance fonctionnelle sont les Lipides Polaires (LP, phospholipides et sphingolipides), le cholestérol, les di- et monoglycérides et les vitamines liposolubles (A, D, E, K). L'objectif de cette partie est de résumer les spécificités des lipides laitiers aux niveaux moléculaire et supramoléculaire concernant les molécules vectrices d'AG majeurs (TG et LP), en soulignant leur potentiel d'intérêt nutritionnel.

\section{1 / Un profil en acides gras com-} plexe et spécifiquement réparti sur les triglycérides

a) Composition en acides gras du lait et structure des triglycérides

Comme chez tous les mammifères, la composition en $\mathrm{AG}$ du lait de vache est influencée par l'alimentation de la vache, sa race, la saison et la localisation géographique ; différentes revues indiquent des profils en $A G$ reflétant ces influences (Chilliard et al 2001, Jensen 2002, Chilliard et al 2007, Lopez 2011). Il faut noter que sur les environ $400 \mathrm{AG}$ représentés dans le lait, une douzaine seulement y sont présents en proportion supérieure à 1\% (MacGibbon et al 2006). Des tendances globales peuvent cependant être résumées concernant le profil en $\mathrm{AG} \mathrm{du}$ lait. Le lait de vache présente la particularité de contenir des $\mathrm{AG}$ à chaînes courtes $(4: 0$ - 6:0) et moyennes (8:0 - 12:0), jusqu'à $15 \%$ en cumulé. Il est également riche en AG saturés à chaîne longue $(>14: 0$, dont du 16:0 pour
20 à $35 \%$ ) et en AG monoinsaturés, notamment l'acide oléique (18:1 n-9 cis pour environ $20-25 \%$ ). La matière grasse laitière est également une source non négligeable d'acides gras essentiels, l'acide alpha-linolénique 18:3 n-3 cis $(0,5$ à $2 \%)$ et l'acide linoléique 18:2 n-6 cis (1 à 3\%) (Jensen 2002). D'autres acides gras spécifiques du lait sont l'acide vaccénique (18:1 trans 11$)$ et les conjugués de l'acide linoléique ou CLA (principalement l'acide ruménique 18:2 cis 9 trans 11, 0,2 à 2\%), issus de la biohydrogénation des acides gras insaturées par les bactéries dans le rumen.

Comme dans l'alimentation en général, ces AG ne sont pas présents sous forme libre dans le lait mais portés principalement par les TG. Or, la composition et la structure des TG de la matière grasse laitière sont tout à fait spécifiques. En effet, la distribution des $A G$ sur les positions $s n-1,2$ et 3 des TG n'y est pas due au hasard. Plus de mille espèces moléculaires de TG coexistent (Michalski 2008). D'après la revue détaillée de Jensen (2002), certains AG sont estérifiés préférentiellement sur certaines positions des TG (tableau 2). Les espèces majoritaires de TG présentes dans le lait sont 
ainsi : 18:1 - 16:0 - 4:0 (4,2\% des TG totaux), 16:0 - 16:0 - 4:0 $(3,2 \%)$ et 16:0 - 14:0 - 4:0 (3,1\%). Si 43\% des espèces moléculaires de TG contiennent au moins 2 acides gras parmi C14:0, C16:0, C18:0 et C18:1, il est important de souligner que $36 \%$ contiennent $\mathrm{C} 4: 0$ ou $\mathrm{C} 6: 0$ (en position $s n-3$ ) en plus de $2 \mathrm{AG}$ à chaîne longue.

\section{b) Impact nutritionnel}

Depuis quelques années, différents travaux ont eu pour objectif de savoir comment modifier le profil en AG du lait de manière à se rapprocher des recommandations nutritionnelles (limitation des AG saturés - AGS - , augmentation des acides gras polyinsaturés - AGPI), notamment par le biais de la qualité de l'alimentation des troupeaux. On peut noter en particulier dans ce contexte les stratégies de supplémentation alimentaire des vaches en graines de lin extrudées par exemple. De premières études d'intervention nutritionnelle suggèrent que ces pratiques de la filière lin présentent des bénéfices pour la santé du consommateur du point de vue du profil en cholestérol et en antioxydants circulants dans le sang (Intorre et al 2011, Malpuech-Brugere et al 2010).

Du point de vue de l'impact métabolique d'AG spécifiques, plusieurs font actuellement l'objet d'une attention particulière (Haug et al 2007). Les AG à chaînes courtes et moyennes sont métabolisés différemment des autres AG : une fois libérés par l'hydrolyse des TG via l'action des lipases gastrique puis pancréatique, ils sont directement absorbés et transportés par la veine porte pour être beta-oxydés par le foie. Ainsi, ils ne contribuent pas au stockage de graisse dans le tissu adipeux ou à la lipotoxicité (Michalski 2009, Mu et al 2004). Par ailleurs, des AG à chaîne courte ont récemment été décrits pour leur effet antibactérien sur des microorganismes oraux (Huang et al 2011). Le rôle potentiel des AG à chaînes courtes et moyennes du lait dans la santé de la sphère orale serait donc important à étudier. D'une manière plus générale, différentes revues soulignent les effets métaboliques spécifiques de chaque type d'AG saturé. L'acide myristique du lait est ainsi capable d'augmenter le HDL cholestérol chez l'Homme. Des effets neutres à bénéfiques de l'acide stéarique ont aussi été observés sur le risque athérogène. Les AGS de différentes longueurs de chaînes exercent aussi des effets anti-inflammatoires, antiviraux et antibactériens dans l'intestin, et participeraient aux mécanismes de défense immunitaire via les HDL (German et al 2010). Chez la souris, un régime enrichi en matière grasse laitière aboutit à une inflammation métabolique plus faible qu'un régime enrichi en huile de palme, également riche en acides palmitique et stéarique, mais dépourvu d'AG à chaînes courtes et moyennes, en lien avec une composition différente du microbiote intestinal (Laugerette et al 2012). Toujours chez le rongeur, une matière grasse laitière riche en acide alpha-linolénique aboutit à une accrétion plus efficace du DHA dans le cerveau qu'un régime dépourvu de matière grasse laitière et enrichi en DHA (Du et al 2012). Ainsi, il convient de ne pas considérer les AGS d'un seul bloc du point de vue de leurs effets physiologiques (Legrand 2008), ce qui est aujourd'hui pris en compte dans les apports nutritionnels conseillés (AFSSA 2010). De ce point de vue, la matière grasse laitière a la spécificité d'en représenter toute la variété.

Le lait contient d'autre part des acides gras insaturés à structures spécifiques. L'acide vaccénique du lait est un acide gras trans de structure différente (18:1 trans 11) de l'acide élaidique (trans 9), son homologue issu des transformations des huiles végétales qui est réputé plus athérogène. Des travaux récents montrent que l'isomère trans 9 est plus incorporé dans les phospholipides des hépatocytes que l'acide vaccénique, au moins in vitro. Ces résultats amènent à se questionner sur le métabolisme hépatique des isomères d'AG trans et aux conséquences sur l'efflux de cholestérol chez l'Homme après consommation de sources laitières ou végétales (Du et al 2011). Un autre type d'AG trans laitier est aujourd'hui source d'attention particulière : l'acide palmitoléique (16:1 n-7 trans). Ce biomarqueur de la consommation de produits laitiers est en effet associé à une diminution de différents facteurs de risque métabolique : triglycéridémie, inflammation, marqueurs anthropométriques, élévation du cholestérol HDL, notamment (Mozaffarian et al 2011). Les CLA font aussi l'objet de nombreux travaux du fait de leur capacité à inhiber la lipogénèse (Kennedy et al 2010). Une étude récente souligne une association entre la concentration de CLA ruménique dans le tissu adipeux et un risque diminué d'infarctus du myocarde chez l'Homme (Smit et al 2010). D'autre part, des effets anti-inflammatoires des CLA sont étudiés (Huebner et al 2010).

Enfin, les AG à chaînes ramifiées sont des espèces mineures dans le lait, présents à une teneur cumulée de environ $2 \%$ (soit environ $200 \mathrm{mg}$ consommés par jour dans l'alimentation nord-américaine), mais sujets à un intérêt croissant du fait de leur bioactivité potentielle (Ran-Ressler et al 2011). C'est le cas notamment de l'acide phytanique (acide $(7 R, 11 R)$ 3,7,11,15-tetramethylhexadécanoique), produit secondaire issu de la fermentation de la chlorophylle dans le rumen.
L'acide phytanique pourrait présenter des effets préventifs sur le syndrome métabolique du fait de son activité décrite comme agoniste des récepteurs nucléaires RXR et PPAR- $\alpha$. Chez l'Homme, sa concentration plasmatique augmenterait avec la consommation de matière grasse laitière, les conséquences métaboliques restant à mettre en évidence (Werner et al 2011).

D'autres travaux s'intéressent actuellement à l'importance de la position des AG sur les TG dans des matières grasses alimentaires sur leur digestion et leur absorption intestinale, ce qui a donné lieu à différentes revues (Berry 2009, Raynal-Ljutovak et al 2011). En effet, la lipase gastrique hydrolysant préférentiellement les acides gras situés en position $s n-3$, et la lipase pancréatique libérant ceux en positions $s n-1$ et $s n-3$, ces AG situés en positions externes sont ainsi libérés sous forme d'AG libre dans la lumière intestinale tandis que l'AG en position centrale des TG reste estérifié sous forme de monoglycéride (Armand 2008b). Cette dernière forme est efficacement absorbée au niveau entérocytaire tandis que parmi les AG gras libres, une petite partie peut avoir des difficultés à être absorbée, comme dans le cas des AG saturés à longue chaîne pouvant former des savons en présence de cations divalents. Chez le nourrisson, l'acide palmitique du lait maternel est particulièrement bien absorbé car il est situé en position $s n-2$ des TG dans le lait humain; nous pouvons noter que dans le lait de vache près de la moitié de l'acide palmitique est également située en $s n-2$, contrairement à d'autres graisses saturées notamment végétales où il est situé en positions externes (Raynal-Ljutovak et al 2011). Chez l'Homme adulte, l'effet de la structure moléculaire des TG ingérés sur la quantité de lipides circulant dans le sang au cours de la digestion semble surtout corrélé à l'état physique de la matière grasse induit par cette structure triglycéridique, avec une moindre absorption pour des matières grasses partiellement solides à température corporelle (Berry 2009, Raynal-Ljutovak et al 2011). Concernant la matière grasse laitière, moins de $5 \%$ des TG sont encore cristallisés à $37^{\circ} \mathrm{C}$ (Lopez 2011). Nous devons aussi rappeler que les AG courts et moyens de la matière grasse laitière sont presque exclusivement en position externe $s n-3$ (Tableau 2 ). Ils sont ainsi rapidement hydrolysés et fournissent une source rapide d'énergie disponible au cours de la digestion (Small 1991). Des études cliniques complémentaires devront permettre de mettre en évidence l'impact nutritionnel de la structure spécifique des TG laitiers par rapport à d'autres sources de matières grasses. 
Tableau 2. Régio-distribution des acides gras majeurs sur les positions sn-1, 2 et 3 des triglycérides du lait (valeurs arrondies) (Michalski 2009, adapté de plusieurs auteurs).

\begin{tabular}{|c|c|c|c|c|}
\hline & & \multicolumn{3}{|c|}{$\%$ molaire sur la position ${ }^{(1)}$} \\
\hline Acide gras & Type de lait & sn-1 & sn-2 & sn-3 \\
\hline Butyrique (4:0) & N.S. ${ }^{(2)}$ & & & 98 \\
\hline Caproique (6:0) & N.S. & & & 93 \\
\hline \multirow{3}{*}{ Caprylique (8:0) } & N.S. & & 43,5 & 52,5 \\
\hline & Teneur faible en $\mathrm{CLA}^{(3)}$ & 0 & 50 & 50 \\
\hline & Teneur élevée en $\operatorname{CLA}^{(3)}$ & 0 & 0 & 100 \\
\hline \multirow{3}{*}{ Caprique (10:0) } & N.S. & & 51,5 & \\
\hline & Teneur faible en CLA & 0 & 32 & 68 \\
\hline & Teneur élevée en CLA & 0 & 18 & 82 \\
\hline \multirow{3}{*}{ Laurique $(12: 0)$} & N.S. & & 60 & \\
\hline & Teneur faible en CLA & 40 & 49 & 11 \\
\hline & Teneur élevée en CLA & 0 & 78 & 22 \\
\hline \multirow{3}{*}{ Myristique (14:0) } & N.S. & & 62 & \\
\hline & Teneur faible en CLA & 9 & 72 & 18 \\
\hline & Teneur élevée en CLA & 11 & 53 & 36 \\
\hline \multirow{3}{*}{ Palmitique (16:0) } & N.S. & 44,5 & 43 & \\
\hline & Teneur faible en CLA & 37 & 40 & 23 \\
\hline & Teneur élevée en CLA & 41 & 42 & 17 \\
\hline \multirow{3}{*}{ Stearique (18:0) } & N.S. & 56 & & 28 \\
\hline & Teneur faible en CLA & 51 & 17 & 32 \\
\hline & Teneur élevée en CLA & 47 & 32 & 21 \\
\hline \multirow{3}{*}{ Oleique (18:1 n-9 cis) } & N.S. & 59 & 0 & 41 \\
\hline & Teneur faible en CLA & 34 & 18 & 48 \\
\hline & Teneur élevée en CLA & 32 & 23 & 45 \\
\hline \multirow{3}{*}{ Linoleic (18:2 n-6 cis) } & N.S. & & 35 & \\
\hline & Teneur faible en CLA & 13 & 19 & 68 \\
\hline & Teneur élevée en CLA & 27 & 26 & 46 \\
\hline \multirow{3}{*}{$\alpha$-Linolenic (18:3 n-3 cis) } & N.S. & & 44 & \\
\hline & Teneur faible en CLA & 47 & 24 & 29 \\
\hline & Teneur élevée en CLA & 34 & 37 & 29 \\
\hline \multirow{3}{*}{ CLA (18:2 9cis, 11trans) } & N.S. & & 26 & \\
\hline & Teneur faible en CLA & 35 & 13 & 52 \\
\hline & Teneur élevée en CLA & 19 & 16 & 65 \\
\hline
\end{tabular}

(1) Sur une ligne, les positions sn associées à des cases vides contiennent la fraction complémentaire de l'acide gras considéré (par exemple, $2 \%$ de l'acide butyrique est estérifié en positions sn-1 et/ou sn-2).

(2) Non Spécifié: matière grasse laitière de beurre ou de produits laitiers achetés localement tel qu'indiqué par les auteurs, ou compilation de valeurs indiquées dans la littérature (Jensen 2002).

(3) Teneur faible en CLA : matière grasse de beurre sélectionnée pour sa faible teneur en acide ruménique $(0,8 \%$ des acides gras totaux) ; Teneur élevée en CLA : matière grasse de fromage Comté sélectionnée pour sa teneur élevée en acide ruménique (2,1\% des acides gras totaux) (Valeille et Martin 2004).

4.2 / Une organisation supramoléculaire sous forme de globules gras entourés d'une membrane riche en lipides polaires

L'impact possible de l'organisation supramoléculaire des lipides dans les aliments sur la digestion et la métabolisation des $\mathrm{AG}$, au-delà de leur simple composition, est désormais mise en avant dans les études nutritionnelles
(Raynal-Ljutovak et al 2011). Ceci constitue une évolution conceptuelle importante qui trouve désormais sa place dans les études d'intervention et les réflexions sur les recommandations nutritionnelles (de Oliveira Otto et al 2012). Cette approche est particulièrement pertinente concernant la matière grasse laitière qui présente différents niveaux d'organisation dans le lait et les produits laitiers (Armand 2008b, Lopez 2011). a) Les globules gras et leur membrane: structure et importance pour la digestion des lipides

Le lait étant une émulsion, les lipides y sont présents sous forme de gouttelettes présentant une structure supramoléculaire unique : les globules gras du lait (Armand 2008b, Michalski 2009, Lopez 2011). La figure $6 \mathrm{~B}$ en montre une représentation schématique $i$ ) à l'état natif au moment de la sécrétion du lait 
et ii) suite aux traitements technologiques d'homogénéisation. Les globules gras sont constitués d'un cœur de TG entourés par une membrane biologique, la MFGM. Celle-ci comprend une monocouche interne de LP dérivée de la membrane du RE qui enrobe les gouttelettes lipidiques lors de leur formation intracellulaire, et d'une bicouche externe correspondant à la membrane biologique de la cellule épithéliale emportée au cours de la sécrétion des globules gras. Entre les deux couches peuvent rester piégées des excroissances cytoplasmiques pouvant ainsi contenir du matériel bioactif comme des ARNm, par exemple. Il est important de souligner que la couche externe de la MFGM présente toutes les caractéristiques structurales des membranes biologiques. Cela inclut en particulier la présence de nombreuses protéines, récepteurs et transporteurs membranaires (Mather 2000), dont des mucines et la xanthine oxydase. Comme c'est le cas pour les membranes biologiques en général, la MFGM présente des caractéristiques structurales d'importance fonctionnelle comme la présence de " radeaux » lipidiques ( « rafts »), qui sont des microdomaines organisés riches en cholestérol et en SphingoMyéline (SM) (Lopez 2011). Toutefois, il est important de noter que cette structure est fortement altérée par le traitement d'homogénéisation utilisé pour stabiliser physiquement le lait pour sa commercialisation (Cousin et al 2009). Les composants de la MFGM sont alors toujours présents dans le lait, mais l'organisation des gouttelettes est drastiquement modifiée, avec un diamètre réduit et l'enrobage des TG avec des caséines et des protéines sériques (figure 6B).

L'importance de cette organisation des lipides, sous forme de globules gras différemment structurés, sur leur digestion, leur absorption et leurs conséquences métaboliques fait l'objet d'un intérêt croissant de la communauté scientifique comme en témoignent différentes revues (Michalski et al 2006a, Raynal-Ljutovak et al 2011). En effet, la lipolyse digestive in vitro de la matière grasse laitière diffère selon la structure des gouttelettes lipidiques (Armand 2008b, Berton et al 2012, Vors et al 2012). Chez le rongeur, des globules gras du lait homogénéisés ou non, et des gouttelettes d'émulsions de matière grasse laitière recouvertes de protéines ou de phospholipides, n'aboutissent pas à la même cinétique de lipémie et de métabolisation des AG au cours de la période de digestion (Michalski et al 2005, Michalski et al 2006b). Une étude clinique récente a testé chez des hommes minces ou obèses, des petits déjeuners de même composition, mais différant uniquement par la structure d'apport de la matière grasse laitière, émulsionnée ou tartinée. Cela aboutit notamment à des différences importantes de cinétique d'absorption des $\mathrm{AG}$ et in fine, à des niveaux de betaoxydation différents de ces AG ingérés (Vors et al 2013). L'importance métabolique sur le long terme de la consommation de matière grasse différemment structurée dans les produits est donc à élucider.

b) Propriétés nutritionnelles des lipides polaires laitiers de la membrane des globules gras

Depuis quelques années, la littérature scientifique sur l'utilisation possible d'extraits de MFGM pour des applications nutritionnelles se développe. Ceci est dû principalement aux propriétés fonctionnelles des lipides polaires laitiers qu'elle contient, ces LP étant décrits dans certains travaux récents comme présentant des effets bénéfiques sur le métabolisme des lipides, la prévention du cancer du côlon et la fonction intestinale (Rombaut et Dewettinck 2006, Argov et al 2008). Différentes revues récentes dressent une liste des nombreuses molécules bioactives présentes dans la MFGM, pouvant se révéler importantes dans les propriétés nutritionnelles des produits laitiers et aboutir à la formulation de nouveaux ingrédients alimentaires (Riccio 2004, Spitsberg 2005, Michalski et al 2006a, Ward et al 2006, Dewettinck et al 2008, Jimenez-Flores et al 2008, Michalski 2009). Parmi ces molécules d'intérêt se trouvent les LP laitiers incluant les sphingolipides (SM, gangliosides et cérébrosides) (Vesper et al 1999), les glycérophospholipides comme la PhosphatidylCholine (PC) et les protéines de la MFGM (mucines dont MUC1, $\mathrm{XO}$, protéines liant les acides gras dont FABP...) (Fong et al 2007).

Du point de vue du métabolisme des lipides, différentes études montrent des bénéfices d'une supplémentation en LP laitiers pour améliorer le métabolisme des TG et du cholestérol notamment au niveau hépatique (Kamili et al 2010, Wat et al 2009). Du point de vue de la digestion, la SM et ses métabolites sont décrits comme limitant l'absorption intestinale du cholestérol et peuvent influencer l'hydrolyse des TG et la synthèse des lipoprotéines (Nilsson et al 2006). L'hydrolyse des TG par la lipase gastrique est en effet réduite si ceux-ci sont contenus dans des gouttelettes couvertes de SM plutôt que de PC (Armand 2008a). D'une manière générale, les LP alimentaires sont réputés pour leurs effets bénéfiques sur le métabolisme hépatique en interférant avec l'absorption des stérols et en stimulant l'excrétion des sels biliaires et du cholestérol (Rampone 1973, Cohn et al 2008). Peu d'études sur les effets métaboliques des LP laitiers ont été effectuées chez l'Homme à ce jour ; les premières tendent à montrer des effets différents sur les lipoprotéines plasmatiques en comparaison avec des phospholipides d'œuf (Ohlsson et al 2009; Ohlsson et al 2010).

En résumé, la fraction lipidique du lait présente une diversité de molécules spécifiques dont le potentiel bioactif de certaines est en cours d'exploration, l'ensemble étant structuré d'une manière spécifique dans les différents produits laitiers pouvant contribuer à leurs effets sur l'organisme.

\section{5 / Les lactosomes}

La plupart des cellules libèrent, lors de la fusion de corps multivésiculaires avec la membrane plasmique, des vésicules membranaires de 40 à $100 \mathrm{~nm}$ de diamètre appelés exosomes. Ils représentent vraisemblablement un moyen de communication intercellulaire et ont maintenant été identifiés dans plusieurs fluides corporels comme le liquide amniotique, le sang, l'urine, la salive mais aussi le lait ; on parle alors de lactosomes (ArgovArgaman et al 2010). Les exosomes expriment un ensemble commun de protéines membranaires et cytosoliques, mais aussi une gamme de protéines qui reflètent la cellule hôte d'origine. La fonction physiologique des exosomes est encore discutée mais les données actuelles, issues de différents systèmes expérimentaux, semblent indiquer qu'ils puissent avoir de multiples fonctions biologiques.

Ils seraient impliqués dans la réponse immunitaire, la présentation des antigènes, la communication intracellulaire et le transfert d'ARN et de protéines.

On sait maintenant que les lactosomes contiennent des quantités importantes de transcrits polyadenylés spécifiant des lactoprotéines majeures, des facteurs d'élongation et de petits ARN (précurseurs de miRNA) qui peuvent être transférés vers d'autres cellules et devenir fonctionnels dans ce nouvel environnement (Hata et al 2010). Ces données suggèrent que ces miRNA sont capables d'agir comme éléments régulateurs de l'acquisition et du développement des défenses immunitaires du jeune, au cours de la période post-natale.

\section{Conclusion}

Au cours des dernières années, il y a eu des avancées certaines sur la structure de la micelle de caséine et du globule gras. Néanmoins on ne dispose toujours pas d'une image unique de la structure interne de la micelle, qui serait essentielle pour acquérir une meilleure maîtrise de 
son potentiel fonctionnel. La démarche idéale pour connaître l'organisation des structures supramoléculaires du lait, structure interne dans le cas de la micelle, organisation de la membrane pour le globule gras, va certainement de pair avec une meilleure compréhension de l'élaboration de ces structures dans la cellule épithéliale mammaire, un processus sur lequel de nombreuses ombres subsistent (rôle fonctionnel des différentes caséines, implication du calcium dans la structuration micellaire...). Il en est de même de la biogénèse du globule gras où deux théories s'opposent au moins pour ce qui concerne la formation des gouttelettes cytoplasmiques, au niveau du RE. Les recherches doivent encore pro- gresser sur la biogénèse de ces structures supramoléculaires dont l'étude se heurte à de nombreux verrous méthodologiques. En revanche, elle a avancé sur le potentiel nutritionnel des lipides du lait dont nous n'avons sans doute pas découvert toute l'étendue et la diversité.

\section{Références}

AFSSA, 2009. Etude Individuelle Nationale des Consommations Alimentaires 2 (INCA2) http://www.anses.fr/Documents/PASER-RaINCA2.pdf

AFSSA, 2010. Avis de l'Agence Française de Sécurité Sanitaire des Aliments relatif à l'actualisation des Apports Nutritionnels Conseillés pour les acides gras. http://www. anses.fr/Documents/NUT2006sa0359.pdf

Alexander L.J., Beattie C.W., 1992. The sequence of porcine beta-casein cDNA. Anim Genet., 23, 369-71.

Argov N., Lemay D.G., German J., 2008. Milk fat globule structure and function nanoscience comes to milk production. Trends Food Sci. Technol., 19, 617-623.

Argov-Argaman N., Smilowitz J.T., Bricarello D.A., Barboza M., Lerno L., Froehlich J.W., Lee H., Zivkovic A.M., Lemay D.G., Freeman S., Lebrilla C.B., Parikh A.N., German J.B., 2010. Lactosomes: Structural and compositional classification of unique nanometer-sized protein lipid particles of human milk. J. Agric. Food Chem., 58, 1123411242 .

Armand M., 2008. Digestibilité des matières grasses chez l'Homme. Sci. Alim., 28, 84-98.

Aslibekyan S., Campos H., Baylin A., 2012. Biomarkers of dairy intake and the risk of heart disease. Nutr. Metab. Cardiovasc. Dis., 22, 1039-1045.

Ballester M., Sánchez A., Folch J.M., 2005. Polymorphisms in the goat $\beta$-lactoglobulin gene. J. Dairy Res., 72, 379-384.

Barbieri M.E., Manfredi E., Elsen J.M., Ricordeau G., Bouillon J., Grosclaude F., Mahé M.F., Bibé B., 1995. Influence du locus de la caséine $\alpha_{\mathrm{s} 1}$ sur les performances laitières et les paramètres génétiques des chèvres de race Alpine. Genet. Sel. Evol., 27, 437-450.

Berry S.E.E., 2009. Triacylglycerol structure and interesterification of palmitic and stearic acid-rich fats: an overview and implications for cardiovascular disease. Nutr. Res. Rev., 22, 3-17.

Berton A., Rouvellac S., Robert B., Rousseau F., Lopez C., Crenon I., 2012. Effect of the size and interface composition of milk fat globules on their in vitro digestion by the human pancreatic lipase: Native versus homogenized milk fat globules. Food Hydrocolloids, 29, 123-134

Bevilacqua C., Ferranti P., Garro G., Veltri C., Lagonigro R., Leroux C., Pietrola E., Addeo F., Pilla F., Chianese L., Martin P., 2002. Interallelic recombination is likely responsible for the occurrence of a new rare $\alpha_{\mathrm{s} 1}$-casein variant in the goat species. Eur. J. Biochem., 269, 1293-1303.
Bevilacqua C., Helbling J.C., Miranda G., Martin P., 2006. Translational efficiency of casein transcripts in the mammary tissue of lactating ruminants. Reprod. Nutr. Dev., 46, 567-578.

\section{BIOPEP www.uwm.edu.pl/biochemica}

Boirie Y., Dangin M., Gachon P., Vasson M.P., Maubois J.L., Beaufrere B, 1997. Slow and fast dietary proteins differently modulate postprandial protein accretion. Proc. Natl. Acad. Sci. U.S.A., 94, 14930-14935.

Bonsing J., Ring J.M., Stewart A.F., Mackinlay A.G., 1988. Complete nucleotide sequence of the bovine beta-casein gene. Aust. J. Biol. Sci., 41, 527-537.

Bouchoux A., Gesan-Guiziou G., Perez J., Cabane B., 2010. How to Squeeze a Sponge Casein Micelles under Osmotic Stress, a SAXS Study. Biophys. J., 99, 3754-3762.

Ceriotti G., Chessa S., Bolla P., Budelli E., Bianchi L., Duranti E., Caroli A., 2004. Single nucleotide polymorphisms in the ovine casein genes detected by polymerase chain reactionsingle strand conformation polymorphism. J. Dairy Sci., 87, 2606-2613.

Chanat E., Martin P., Ollivier-Bousquet M. 1999. $\alpha_{\mathrm{s} 1}$-casein is required for the efficient transport of $\beta$ - and $\kappa$-casein from the endoplasmic reticulum to the Golgi apparatus of mammary epithelial cells. J. Cell Sci., 112, 3399-3412.

Chianese L., Garro G., Mauriello R., Laezza P., Ferranti P., Addeo F, 1996. Occurrence of five $\alpha_{\mathrm{s} 1}$-casein variants in ovine milk. J. Dairy Res., 63, 49-59.

Chilliard Y., Ferlay A., Doreau M., 2001 Contrôle de la qualité nutritionnelle des matières grasses du lait par l'alimentation des vaches laitières : acides gras trans, polyinsaturés, acide linoléique conjugué. In : Numéro spécial, Matières grasses alimentaires et qualite des produits. INRA Prod. Anim., 14, 323-335.

Chilliard Y., Glasser F., Ferlay A., Bernard L., Rouel J., Doreau M., 2007. Diet, rumen biohydrogenation and nutritional quality of cow and goat milk fat. Eur. J. Lipid Sci. Technol., $109,828-855$

Clare D.A., Swaisgood H.E., 2000 Bioactive milk peptides: a prospectus. J. Dairy Sci., 83, 1187-1195.

Cohn J.S., Wat E., Kamili A., Tandy S. 2008. Dietary phospholipids, hepatic lipid metabolism and cardiovascular disease. Curr Opin. Lipidol., 19, 257-262.

Coll A., Folch J.M., Sanchez A., 1995. Structural features of the 5' flanking region of the caprinek-casein gene. J. Dairy Sci., 78, 973-977.
Cousin O., Michalski M.C., 2009. Influence des technologies sur les caractéristiques nutritionnelles de la matière grasse laitière : à l'usine. Sci. Alim., 29, 21-34.

Couvreur S., Hurtaud C., 2007. Le globule gras du lait : sécrétion, composition, fonctions et facteurs de variation. INRA Prod. Anim., 20, 369-382.

Dalgleish D., 2011. On the structural models of bovine casein micelles - review and possible improvements. Soft Matter, 7, 2265-2272.

Dalgleish D., Corredig M., 2012. The structure of the casein micelle of milk and its changes during processing. Annu. Rev. Food Sci. Technol., 3, 449-467.

deKruif C.G., Holt C., 2003. Casein micelle structure, functions and interactions. In: Advanced Dairy Chemistry, Volume 1, proteins, $3^{\text {rd }}$ edition. Fox P.F., McSweeney P.L.H. (Eds). Kluwer Academic/Plenum Publishers, New York, USA, 213-276.

deKruif C.G., Huppertz T., Urban V.S. Petukhov A.V., 2012. Casein micelles and their internal structure. Adv. Colloid Interface Sci., 171, 36-52.

de Oliveira Otto M.C., Mozaffarian D., Kromhout D., Bertoni A.G., Sibley C.T., Jacobs D.R.J., Nettleton J.A., 2012. Dietary intake of saturated fat by food source and incident cardiovascular disease: the MultiEthnic Study of Atherosclerosis. Am. J. Clin. Nutr., 96, 397-404.

Dewettinck K., Rombaut R., Thienpont N., Le T.T., Messens K., Van Camp J., 2008. Nutritional and technological aspects of milk fat globule membrane material. Int. Dairy J., $18,436-457$

Du Q., Martin J.C., Agnani G., Pages N., Leruyet P., Carayon P., Delplanque B., 2012. Dairy fat blends high in $\alpha$-linolenic acid are superior to n-3 fatty-acid-enriched palm oil blends for increasing DHA levels in the brains of young rats. J. Nutr. Biochem., 23, 1573 1582

Du Z.Y., Degrace P., Gresti J., Loreau O., Clouet P., 2011. Vaccenic and elaidic acid equally esterify into triacylglycerols, but differently into phospholipids of fed rat liver cells. Lipids, 46, 647-57.

Dupont D., Johansson A., Marchin S., RoletRepecaud O., Marchesseau S., Léonil J., 2011. Topography of the Casein Micelle Surface by Surface Plasmon Resonance (SPR) Using a Selection of Specific Monoclona Antibodies. J. Agric. Food Chem., 59, 8375 8384.

FAPRI 2009.US \& World Agricultural Outlook Database. 
Farrell H., Malin E., Brown E., Qi P.X., 2006. Casein micelle structure: What can be learned from milk synthesis and structural biology? Curr. Opin. Colloid Interface Sci. $11,135-147$

Ferranti P., Addeo F., Malorni A., Chianese L., Leroux C., Martin P., 1997. Differential splicing of pre-messenger RNA produces multiple forms of goat $\alpha_{\mathrm{s} 1}$-casein. Eur. J. Biochem., 249, 1-7.

Fong B.Y., Norris C.S., MacGibbon A.K 2007. Protein and lipid composition of bovine milk-fat-globule membrane. Int. Dairy J., 17, 275-288.

German J.B., Dillard C.J., 2010. Saturated fats: a perspective from lactation and milk composition. Lipids, 45, 915-923

Groenen M.A.M., Dijkhof R.J.M., Verstege A.J.M., van der Poel J.J., 1993.The complete sequence of the gene encoding bovine $\alpha_{\mathrm{s} 2}$ casein. Gene, 123, 187-193.

Grosclaude F., Martin P., 1997.Casein Polymorphisms in the goat. IDF-FIL Seminar on Milk protein polymorphism. Palmerston North, New Zealand, 241-253.

Hata T., Murakami K., Nakatani H., Yamamoto Y. Matsuda T. Aoki N., 2010. Isolation of bovine milk-derived microvesicles carrying mRNAs and microRNAs. Biochem. Biophys. Res. Commun., 396, 528-533.

Haug A., Hostmark A.T., Harstad O.M., 2007. Bovine milk in human nutrition - a review. Lipids Health Dis., 25, 6-25.

Holt C., 1985. The size distribution of bovine casein micelles - a review. Food Micro-structure 4, 1-10.

Holt C., 1992. Structure and stability of bovine casein micelles. Adv. Prot. Chem., 43 63-151.

Holt C., 1998. Casein micelle substructure and calcium phosphate interactions studied by sephacryl column chromatography. J. Dairy Sci., 81, 2994-3003.

Holt C., Horne D S, 1996. The hairy casein micelle, Evolution of the concept and its implications for dairy technology. Neth. Milk Dairy J., 50, 85-111.

Horne D.S., 1998. Casein interactions, Casting light on the black boxes, the structure in dairy products. Int. Dairy J., 8, 171-177.

Horne D.S., 2006. Casein micelle structure, Models and muddles. Curr. Opin. Colloid Interface Sci., 11, 148-153.

Huang C.B., Alimova Y., Myers T.M. Ebersole J.L., 2011. Short- and medium-chain fatty acids exhibit antimicrobial activity for oral microorganisms. Arch Oral Biol., 56, 650 654.

Huebner S.M., Campbell J.P., Butz D.E Fulmer T.G., Gendron-Fitzpatrick A., Cook M.E., 2010. Individual isomers of conjugated linoleic acid reduce inflammation associated with established collagen-induced arthritis in DBA/1 mice. J. Nutr., 140, 1454-1461.

Intorre F., Foddai M.S., Azzini E., Martin B., Montel M.C., Catasta G., Toti E., Finotti E., Palomba L., Venneria E., Raguzzini A., Fumagalli A., Testa M.F., Rossi L., Maiani G. 2011. Differential effect of cheese fatty acid composition on blood lipid profile and redox status in normolipidemic volunteers: a pilot study. Int. J. Food Sci. Nutr., 62, 660-669.
Jeantet R., Croguennec T., Mahaut M., Schuck P., Brulé G., 2008. Les produits Laitiers, Edition TEC et DOC, Lavoisier, 185p.

Jensen R.G., 2002. The composition of bovine milk lipids: January 1995 to December 2000. J. Dairy Sci., 85, 295-350.

Jimenez-Flores R., Brisson G., 2008. The milk fat globule membrane as an ingredient: why, how, when? Dairy Sci. Technol., 88, 518 .

Jolivet G., Devinoy E., Fontaine M.L., Houdebine L.M., 1992. Structure of the gene encoding rabbit alpha s1-casein. Gene 113 , 257-262.

Kamili A., Wat E., Chung R., Tandy S. Weir J., Meikle P., Cohn J., 2010. Hepatic accumulation of intestinal cholesterol is decreased and fecal cholesterol excretion is increased in mice fed a high-fat diet supplemented with milk phospholipids. Nutr. Metab. 7,90 .

Kawasaki K., Weiss KM., 2003. Mineralized tissue and vertebrate evolution: the secretory calcium-binding phosphoprotein gene cluster Proc. Natl. Acad. Sci., U.S.A., 100, 4060-4065.

Kennedy A., Martinez K., Schmidt S. Mandrup S., LaPoint K., McIntosh M., 2010. Antiobesity mechanisms of action of conjugated linoleic acid. J. Nutr. Biochem., 21, 171179

Koczan D., Hobom G., Seyfert H.M., 1991. Genomic organization of the bovine alpha-S casein gene. Nucleic Acids Res., 19, 55915596

Korhonen, H. 2009. Milk-derived bioactive peptides: from science to applications. J. Funct. Food, 1, 177-187.

Laugerette F., Furet J.P., Debard C., Daira P., Loizon E., Geloen A., Soulage C.O Simonet C., Lefils-Lacourtablaise J., BernoudHubac N., Bodennec J., Peretti N., Vidal H. Michalski M.C., 2012. Oil composition of high dat diet affects differentlymetabolic inflammation in connexion with endotoxin receptors in mice. Am. J. Physiol. Endocrinol. Metab. 302, E374-E386.

Le Parc A., Léonil J., Chanat E., 2010. $\alpha_{\mathrm{s} 1}$ casein, which is essential for efficient ER-toGolgi casein transport, is also present in tightly membrane-associated form. BMC Cell Biol., 11, 65 .

Legrand P., 2008. Intérêt nutritionnel des principaux acides gras des lipides du lait. CHOLEDOC, CERIN

Lemay D.G., Lynn D.J., Martin W.F., Neville M.C., Casey T.M., Rincon G., Kriventseva E.V., Barris W.C., Hinrichs A.S Molenaar A.J., Pollard K.S., Maqbool N.J., Singh K., Murney R., Zdobnov E.M., Tellam R.L., Medrano J.F., German J.B., Rijnkels M., 2009. The bovine lactation genome: insights into the evolution of mammalian milk. Genome Biol., R43.

Lenasi T., Peterlin B.M., Dove P., 2006 Distal regulation of alternative splicing by splicing enhancer in equine beta-casein intron 1. RNA $12,498-507$

Leroux C., Mazure N., Martin, P., 1992. Mutation away from splice site recognition sequences might cis-modulate alternative splicing of goat $\alpha_{\mathrm{s} 1}$-casein transcript. Structural organization of the relevant gene. J. Biol. Chem., 267, 6147-6157.
Linzell J.L, Peaker M., 1971. Mechanism of milk secretion. Physiol. Rev., 51, 564-597.

Lopez C., 2011. Milk fat globules enveloped by their biological membrane: Unique colloidal assemblies with a specific composition and structure. Curr. Opin. Colloid Interface Sci., 16, 391-404.

MacGibbon A.K.H., Taylor M.W., 2006. Composition and structure of bovine milk lipids. Advanced Dairy Chemistry. Vol. 2: Lipids. Fox. P.F., McSweeney P.L.H. (Eds). Springer. 2, New-York, 1-42.

Malpuech-Brugere C., Mouriot J., BoueVaysse C., Combe N., Peyraud J.L., LeRuyet P., Chesneau G., Morio B., Chardigny J.M., 2010. Differential impact of milk fatty acid profiles on cardiovascular risk biomarkers in healthy men and women. Eur. J. Clin. Nutr., $64,752-759$

Marchin S., Putaux J.L., Pignon F., Léonil J., 2007. Effects of the environmental factors on the casein micelle structure studied by cryo transmission electron microscopy and small-angle $\mathrm{x}$-ray scattering/ultrasmallangle x-ray scattering. J. Chem. Phys., 126, 045101 .

Martin P., Brignon G., Furet J.P., Leroux C., 1996. The gene encoding $\alpha_{\mathrm{s} 1 \text {-casein is }}$ expressed in human mammary epithelial cells during lactation. Lait, 76, 523-535.

Martin P., Ollivier-Bousquet M., Grosclaude F., 1999. Genetic polymorphism of caseins: tool to investigate casein micelle organization. Int. Dairy J., 9, 163-171.

Martin P., Szymanowska M., Zwierzchowski L., Leroux C., 2002. The impact of genetic polymorphisms on the protein composition of ruminants milks. Reprod. Nutr. Dev., 42, 433 459.

Mather I.H., 2000. A review and proposed nomenclature for major proteins of the milk-fat globule membrane. J. Dairy Sci., 83, 203-247.

Maubois J.L., Léonil J., 1989. Peptides du lait à activité biologique. Lait, 69, 245-269.

McMahon D.J., Oommen B.S., 2008. Supramolecular structure of the casein micelle. J. Dairy Sci., 91, 1709-1721.

Meisel H., 2005. Biochemical properties of peptides encrypted in bovine milk proteins. Curr. Med. Chem., 12, 1905-1919.

Michalski M.C., 2008. Structure des triglycérides de la matière grasse laitière et facteurs de risque cardiovasculaire. Sci. Alim., 28, 150155 .

Michalski M.C, 2009. Specific molecula and colloidal structures of milk fat affecting lipolysis, absorption and postprandial lipemia. Eur. J. Lipid Sci. Technol., 111, 413-431.

Michalski M.C., Januel C., 2006a. Does homogenization affect the human health properties of cow's milk? Trends Food Sci. Technol. $17,423-437$.

Michalski M.C., Briard V., Desage M. Geloen A., 2005. The dispersion state of milk fat influences triglyceride metabolism in the rat - A (CO2)-C-13 breath test study. Eur. J. Nutr., 44, 436-444.

Michalski M.C., Soares A.F., Lopez C. Leconte N., Briard V., Geloen A., 2006b. The supramolecular structure of milk fat influences plasma triacylglycerols and fatty acid profile in the rat. Eur. J. Nutr., 45, 215-224. 
Miclo L., Girardet J.M., Egito A.S., Molle D. Martin P., Gaillard J.L., 2007. The primary structure of a low-Mr multiphosphorylated variant of beta-casein in equine milk. Proteomics 7, 1327-1335.

Milenkovic D., Martin P., Guerin G., Leroux C., 2002. A specific pattern of splicing for the horse $\alpha_{\mathrm{s} 1}$-Casein mRNA and partial genomic characterization of the relevant locus. Genet. Sel. Evol., 34, 509-519.

Miranda G., Mahé M.F., Leroux C., Martin P., 2004. Proteomic tools to characterize the protein fraction of Equidae milk. Proteomics 4, 2496-2509.

Moffatt P, Smith CE, St-Arnaud R, Nanci A., 2008. Characterization of Apin, a secreted protein highly expressed in tooth-associated epithelia. J. Cell Biochem., 15, 941-56.

Mozaffarian D., Cao H., King I.B., Lemaitre R.N., Song X., Siscovick D.S., Hotamisligil G.S., 2011. Trans-palmitoleic acid, metabolic risk factors, and new-onset diabetes in U.S. adults: a cohort study. Ann. Intern. Med., 153, 790-799.

Mu H.L., Hoy C.E., 2004.The digestion of dietary triacylglycerols. Progress in Lipid Research, 43, 105-133.

Ng-Kwai-Hang K.F., Grosclaude F., 2003. Genetic polymorphism of milk proteins. In: Advanced Dairy Chemistry, Vol. 1: Proteins. Fox P.F. McSweeney P.L.H., $3^{\text {rd }}$ Ed. NewYork: Kluwer Academic/Plenum Publishers, 737-814.

Nilsson A., Duan R.D., 2006. Absorption and lipoprotein transport of sphingomyelin. J. Lipid Res., 47, 154-171.

Ohlsson L., Burling H., Nilsson A., 2009. Long term effects on human plasma lipoproteins of a formulation enriched in butter milk polar lipid. Lipids Health Dis., 8 .

Ohlsson L., Burling H., Duan R.D., Nilsson A., 2010. Effects of a sphingolipid-enriched dairy formulation on postprandial lipid concentrations. Eur. J. Clin. Nutr., 64, 1344-1349.

Ono T., Obata T., 1989. A Model for the Assembly of Bovine Casein Micelles from F2 and F3 Subunits. J. Dairy Res., 56, 453-461.

Prinzenberg E.M., Gutscher K., Chessa S., Caroli A., Erhardt G., 2005.Caprinek-casein (CSN3) polymorphism: new developments in molecular knowledge. J. Dairy Sci., 88, 14901498.

Phelan M., Aherne A., FitzGerald R.J., O'Brien N.M., 2009. Casein-derived bioactive peptides: Biological effects, industrial uses, safety aspects and regulatory status. Int. Dairy J., 19, 643-654.

Rampone A.J., 1973. Effect of lecithin on intestinal cholesterol uptake by rat intestine in-vitro. J. Physiol., 229, 505-514.

Ran-Ressler R., Sim D., O'Donnell-Megaro A., Bauman D., Barbano D., Brenna J., 2011. Branched chain fatty acid content of United States retail cow's milk and implications for dietary intake. Lipids, 46, 569-576.

Raynal-Ljutovac K., Bouvier J., Gayet C., Simon N., Joffre F., Fine F., Vendeuvre J.,
Lopez C., Chardigny J., Michalski M., Genot C., 2011. Organisation structurale et moléculaire des lipides dans les aliments : impacts possibles sur leur digestion et leur assimilation par l'Homme. Oléagineux Corps gras Lipides, $18,324-351$.

Rhoads R.E., Grudzien-Nogalska E., 2007. Translational regulation of milk protein synthesis at secretory activation. J. Mammary Gland Biol. Neoplasia, 12, 283-292.

Ricci-Cabello I., Herrera M.O., Artacho R., 2012. Possible role of milk-derived bioactive peptides in the treatment and prevention of metabolic syndrome. Nutr. Rev., 70, 241255.

Riccio P., 2004. The proteins of the milk fat globule membrane in the balance. Trends Food Sci. Technol., 15, 458-461.

Rijnkels M., Elnitski L., Miller W., Rosen, J.M., 2003. Multispecies comparative analysis of mammalian-specific genomic domain encoding secretory proteins. Genomics, 82, 417-432.

Rombaut R., DewettinckK., 2006. Properties, analysis and purification of milk polar lipids. Int. Dairy J., 16, 1362-1373.

Sacchi P., Chessa S., Budelli E., Bolla P., Ceriotti G., Soglia D., Rasero R., Cauvin E., Caroli A., 2005. Casein haplotype structure in five Italian goat breeds. J. Dairy Sci., 88, 15611568.

Schmidt D., 1982. Association of caseins and casein micelle structure. P.F. Fox (Ed), Developments in Dairy Chemistry, Appl. Sci. Publ., Barking, UK, 61-86.

Small D.M., 1991.The effects of glyceride structure on absorption and metabolism. Annu. Rev. Nutr., 11, 413-434.

Smit L.A., Baylin A., Campos H., 2010. Conjugated linoleic acid in adipose tissue and risk of myocardial infarction. Am. J. Clin. Nutr., 92, 34-40.

Spitsberg V.L., 2005. Bovine milk fat globule membrane as a potential nutraceutical. J. Dairy Sci., 88, 2289-2294.

Trejo R., Dokland T., Jurat-Fuentes J., Harte F., 2011. Cryo-transmission electron tomography of native casein micelles from bovine milk. J. Dairy Sci., 94, 5770-5775.

Valeille K., Martin J.C., 2004. Complete stereospecific determination of conjugated linoleic acids in triacylglycerol of milk-fat. Reprod. Nutr. Dev., 44, 459-464.

Vesper H., Schmelz E.M., NikolovaKarakashian M.N., Dillehay D.L., Lynch D.V. Merrill A.H., 1999. Sphingolipids in food and the emerging importance of sphingolipids to nutrition. J. Nutr., 129, 1239-1250.

Vors C., Capolino P., Guerin C., Meugnier E., Pesenti S., Chauvin M.A., Monteil J., Peretti N., Cansell M., Carriere F., Michalski M.C., 2012. Coupling in vitro gastrointestinal lipolysis and Caco-2 cell cultures for testing the absorption of different food emulsions. Food Funct., 3, 537-546.

Vors C., Pineau G., Gabert L., Drai J., Louche-Pélissier C., Defoort C., Lairon D., Désage M., Danthine S., Lambert-Porcheron
S., Vidal H., Laville M., Michalski M.C., 2013. Modulating absorption and postprandial handling of dietary fatty acids by structuring fat in the meal: a randomized crossover clinical trial. Am. J. Clin. Nutr., 97, 23-36. doi: 10.3945/ajcn.112.043976. Epub 2012 Dec 12.

Walstra P., 1999. Casein sub-micelles, do they exist? Int. Dairy J., 9, 189-192.

Walstra P., Geurts T.G., Noomen A., Jellemen A., van Boeke M.A.J.S., 1999. Dairy Technology: Principes of Milk Porperties and Processes, 794p.

Walstra P., Jenness R., 1984. Casein micelles. In: Dairy chemistry and physics. Walstra P., Jenness R. (Eds). USA, John Wiley \& Sons, 229-253.

Ward, R.E., German J.B., Corredig M., 2006. Composition, applications, fractionation, technological and nutritional significance of milk fat globule membrane material. Adv. Dairy Chem., Vol. 2: Lipids, $3^{\text {rd }}$ Ed. Fox P.F., McSweeney P.L.H. (Eds). Springer, New-York, 213-244.

Warren W.C., Hillier L.W., Marshall Graves J.A., Birney E., Ponting C.P., Grützner F., Belov K., Miller W., Clarke L., Chinwalla A.T., Yang S.P., Heger A., Locke D.P., Miethke P., Waters P.D., Veyrunes F., Fulton L., Fulton B., Graves T., Wallis J., Puente X.S., López-Otín C., Ordóñez G.R., Eichler E.E., Chen L., Cheng Z., Deakin J.E., Alsop A. Thompson K., Kirby P., Papenfuss A.T., Wakefield M.J., Olender T., Lancet D., Huttley G.A., Smit A.F., Pask A., Temple-Smith P., Batzer M.A., Walker J.A., Konkel M.K., Harris R.S., Whittington C.M., Wong E.S., Gemmell N.J., Buschiazzo E., Vargas Jentzsch I.M., Merkel A., Schmitz J., Zemann A, Churakov G., Kriegs J.O., Brosius J., Murchison E.P., Sachidanandam R., Smith C., Hannon G.J., Tsend-Ayush E., McMillan D., Attenborough R., Rens W., Ferguson-Smith M., Lefèvre C.M., Sharp J.A., Nicholas K.R., Ray D.A., Kube M., Reinhardt R., Pringle T.H., Taylor J., Jones R.C., Nixon B., Dacheux J.L., Niwa H., Sekita Y., Huang X., Stark A., Kheradpour P., Kellis M., Flicek P., Chen Y., Webber C., Hardison R., Nelson J., Hallsworth-Pepin K., Delehaunty K., Markovic C., Minx P., Feng Y., Kremitzki C., Mitreva M., Glasscock J., Wylie T., Wohldmann P., Thiru P., Nhan M.N., Pohl C.S., Smith S.M., Hou S., Nefedov M., de Jong P.J., Renfree M.B., Mardis E.R., Wilson R.K., 2008. Genome analysis of the platypus reveals unique signatures of evolution. Nature, 453, 175-183.

Wat E., Tandy S., Kapera E., Kamili A., Chung R.W., Brown A., Rowney M., Cohn J.S., 2009. Dietary phospholipid-rich dairy milk extract reduces hepatomegaly, hepatic steatosis and hyperlipidemia in mice fed a high-fat diet. Atherosclerosis, 205, 144-150.

Waugh D.F., Creamer L.K., Slattery C.W., Dresdner G.W., 1970. Core polymers of casein micelles. Biochemistry, 9, 786-795.

Werner L.B., Hellgren L.I., Raff M., Jensen S.K., Petersen R.A., Drachmann T., Tholstrup T., 2011. Effect of dairy fat on plasma phytanic acid in healthy volunteers - a randomized controlled study. Lipids Health Dis., 10, 95. 


\title{
Résumé
}

La présence d'une diversité de molécules spécifiques qui coexistent dans le lait sous forme de structures supramoléculaires, telles les micelles de caséine et les globules gras, fait de ce fluide biologique un système extraordinairement complexe, physiquement stable, capable de vectoriser les composés bioactifs présents aussi bien dans sa fraction protéique que dans sa fraction lipidique. Les avancées réalisées tant sur la composition que sur l'organisation structurale de ces structures, même s'il subsiste des zones d'ombre, nous montrent que cette organisation n'est pas sans importance sur les effets qu'elles exercent sur l'organisme. La mise en évidence dans le lait de nanovésicules sécrétées par la cellule épithéliale mammaire (lactosomes) et capables de transmettre à d'autres cellules ou organismes des informations d'une autre nature constitue, à cet égard, un nouveau champ d'investigation passionnant.

\begin{abstract}
Supramolecular structures of milk: structure and nutritional impact of the casein micelle and the milk fat globule

The variety of specific molecules that exist in milk as supramolecular structures, such as casein micelles and fat globules, make this extraordinarily complex and physically stable biological fluid system, able to vectorize bioactive compounds both in the protein and the lipid fractions. Progress made on both the composition and the structural organisation of these structures, although there are still shadowy areas, show that this organisation is not without significance on the effect they have on the organism. The presence in milk of nanovesicles secreted by the mammary epithelial cell (lactosomes) and capable of transmitting molecular information to other cells or organisms is, in this regard, a new exciting field of investigation.
\end{abstract}

LÉONIL J., MICHALSKI M.-C., MARTIN P., 2013. Les structures supramoléculaires du lait : structure et impact nutritionnel de la micelle de caséine et du globule gras. In : Numéro spécial, La vache et le lait. Faverdin P., Leroux C., Baumont R. (Eds). INRA Prod. Anim., 26, 2, 129-144. 